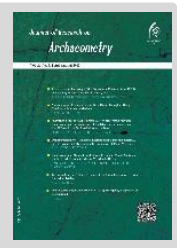

\title{
Study of the traces of nature in herbal deposits of a thousand-year-old Alembic glass analyzed and processed by the Gas Chromatography-Mass Spectrometry (GC-MS) technique
}

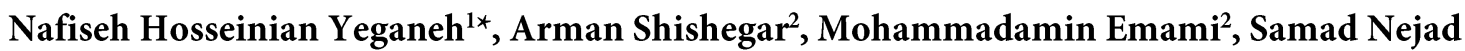 \\ Ebrahimi $^{4}$ \\ ${ }^{1}$ PhD in Archeology, Islamic Azad University Central Tehran Branch, Tehran, IRAN \\ ${ }^{2}$ Assistant Professor and Scientific member of Iranian Center for Archaeological Research (ICAR), Tehran, \\ IRAN \\ ${ }^{3}$ Associate Professor at Department of Conservation of Cultural Properties and Archaeometry, Art \\ University of Isfahan, Isfahan, IRAN-Professor invite at IRAMAT Institute for Research on Archeomaterial, \\ University Bordeaux Montaigne, FRANCE \\ ${ }^{4}$ Assistant Professor at Department of Phytochemistry, Medicinal Plants and Drugs Research Institute, \\ Shahid Beheshti University, Tehran, IRAN
}

\author{
Received: 18/04/2020
}

Accepted: $17 / 06 / 2020$

\begin{abstract}
During the Islamic periods, the containers characterized by narrow or pear-shaped glass-body with a round bottom and long drainage pipe or tube were known, but rarely have been studied. There are three different hypotheses for applications of such containers. A cupping glass(Shakh-i hajamat) for phlebotomize in medicine, "Alembic" for chemical or alchemical experiments, or containers for pharmaceuticals and the production of cosmetics and perfumes which has been used for making the materials and transfer them through tubes, or perfume containers as particular container for cosmetics. It seems that if the container is placed from the opening on a surface, then its pipe is wholly bent in the opposite direction of the body. Where it is taller than the body, it could be used or applied as a cupping glass for phlebotomize in medicine or as a container for materials in medications, cosmetics and perfumery. If the pipe is entirely straight and perpendicular to the body or slightly curved, it could be used for all three applications mentioned above. In Islamic periods, the Arabic word of KIMIA (elixir) was synonymous with alchemy and chemistry in the viewpoint of technology and therefore, includes a variety of processes, including distillation of herbs and medicinal oils, perfumes and rosewater, and fragrant oils and other substances. Some of tools and equipment used for alchemy have been made of glass like the distiller. There have been many pacts for using these kinds of container in the Islamic literature written by Abu Musa Jaber Ibn Hayyan (Around 721 to 815 AD) and Abū Bakr Muhammad ibn Zakariyyā al-Rāzī (865 to 923 AD) who were known as the greatest scientists in the history of chemistry and chemical technology in the Islamic world. Their scientific and practical works have had a great impact on the scientists and researchers of the next generations, both Muslims and Europeans. Many methods, such as distillation and all kinds of basic related tools, such as Cucurbit (qar'a) and Alembic (al-inbī) have been attributed to Jabir Ibn Hayyan. However, al-Razi in his book, Kitab al-asrar or Secret of alchemy, among the tools and devices for chemical processing (Tadbir) and distillation (Taqtir), has mentioned to them and studied the Cucurbit and Alembic with an outlet pipe, a distilled liquid
\end{abstract}

*Corresponding author: n.hosseinian.y@gmail.com

Copyright $(2020$, the Authors / This open-access article is published under the terms of the Creative Commons Attribution-NonCommercial 4.0 International License which permits Share (copy and redistribute the material in any medium or format) and Adapt (remix, transform, and build upon the material) under the Attribution-

NonCommercial .terms 
container, recipient (qabila) and a blind Alembic (without an outlet pipe) (anbiq al'aemaa). As a matter of fact, the chemical composition of materials inside such containers discovered in Iran has not yet been studied, while it is a critical issue for the characterization and application of these containers. For the first time, one of such containers with a long and straight tube which was kept in the Glassware and Ceramic Museum of Iran has been analyzed and processed by the Gas Chromatography-Mass Spectrometry (GC-MS) technique. The analysis of chemical compounds detected in this container revealed that it had been exposed to essential, and natural oils for a long time. The GC-MS analysis of the washing solution led to the identification of 22 substances, where the main identified compounds were: thymol, carvacrol, $\mathrm{p}$-cymene and $\gamma$-terpinene, fatty acids (palmitic acid and stearic acid), and a significant number of substances of the waxes groups. Thymol and carvacrol are the main substances of natural essential oils of Thyme, Savory and Marjoram. Also, the findings of this research have proved the contact of the above-mentioned container with natural essential oils, especially thyme. The ingredients found in this container could be recognizable in many distillates. So, it can suggest that the container has been used as an Alembic for distillation and extraction of vegetable and volatile oil substances in pharmacy, cosmetics and perfumes. More analysis in the future on the contaminated materials within such containers can give more clues and advantages for clarifying the more possible application of these containers.

Keywords: Glass, Alembic, GC-MS, The Glassware Museum, Islamic periods, Essential oil 


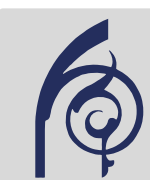

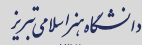

باسستالعندم

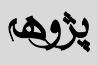
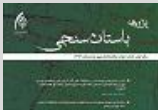

URL: http://jra-tabriziau.ir/

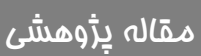

بررسى ردياى طبيعت در نهشتههاى كياهى يك انبيق شيشهاى

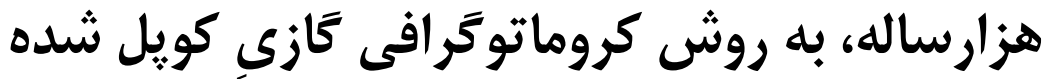

با طيفسنج جرمى (GC-MS)

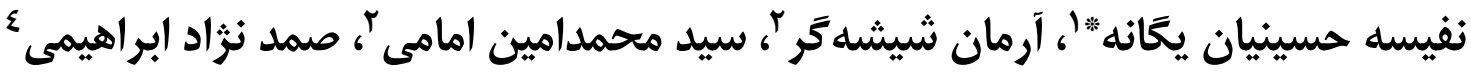

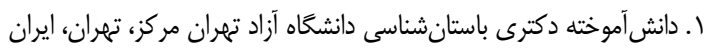

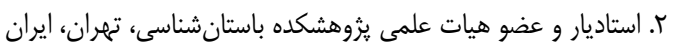

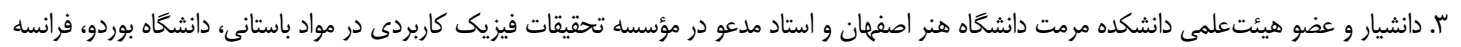

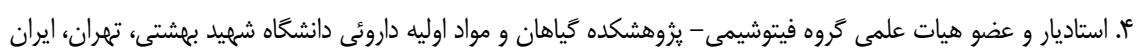

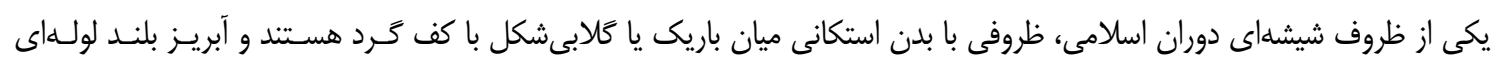

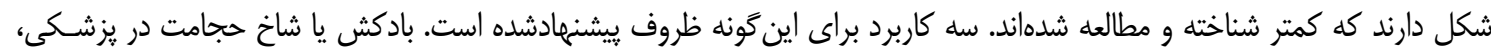

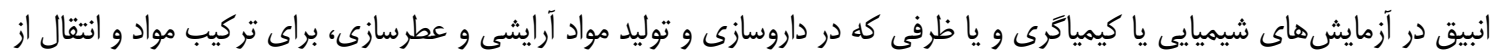

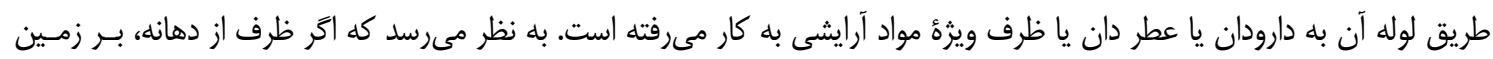

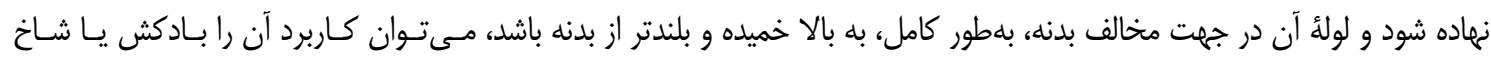

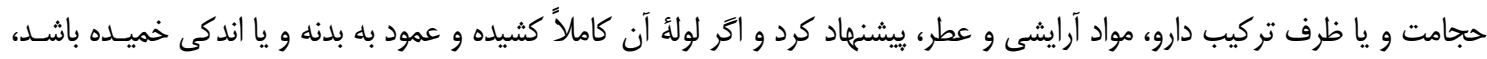

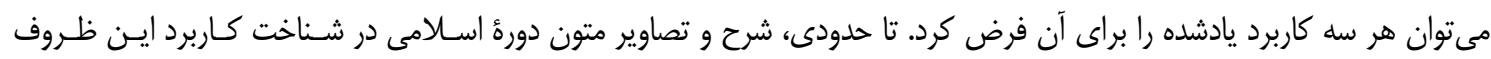

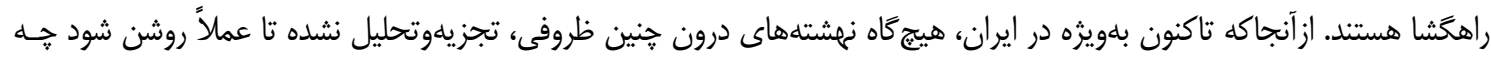

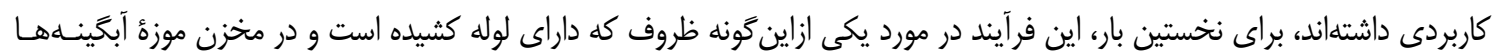

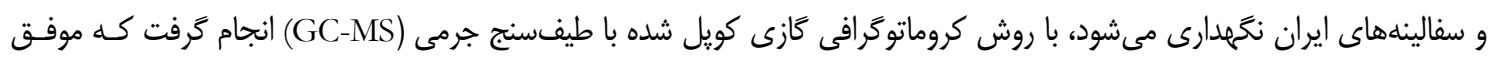

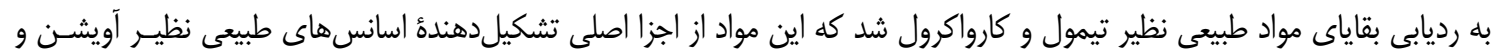

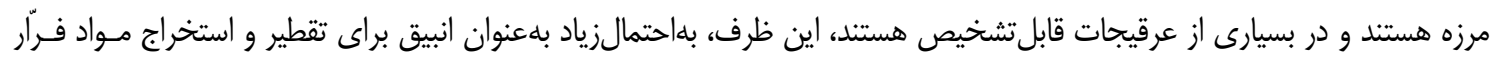

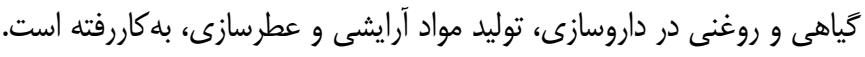

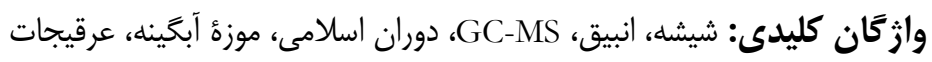

" مسئول مكاتبات: تهران، خيابان انقلاب، دانشخاه تهران، يرديس هنرهاى زيبا، گروه نقاشى و مجسمهسازى

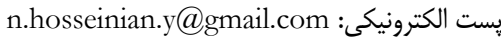
C) حت نشر متعلق به نويسنده(كان) است و نويسنده تحت مجوز Creative Commons Attribution License به مجله اجازه مىدهد مقاله خاب شده را با ديكران به اشتراك بكذارد منوط بر اينكه حقوق مؤلف اثر حفظ و بهن مجنه انتشار اوليه مقاله در اين مجله اشاره شود. 
ظرف تقطيرشده است؟ درصورتى كه ظرف كاربرد تركيـب

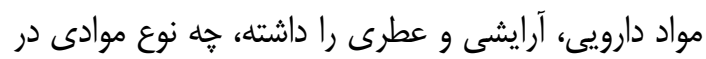

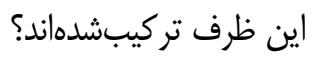

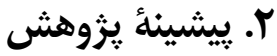

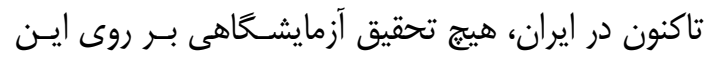

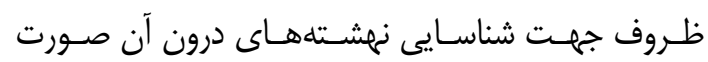

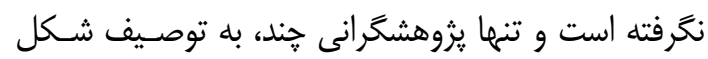

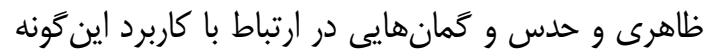
ظروف، يرداختهاند.

\section{". نتاهى بله ييشينه كيمياتَرى، يزشكى،}

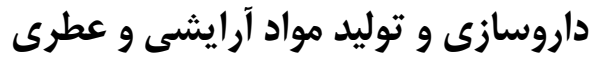

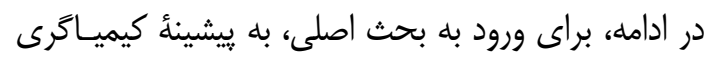

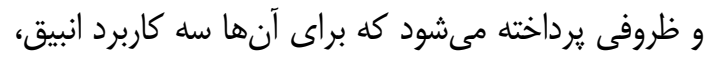

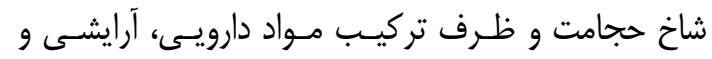

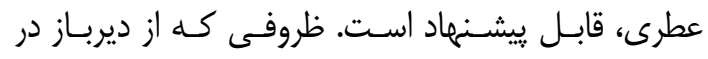
يزشكى، داروسازى و توليد مواد آرايشى و عطــى كـى كـاربرد داشتهاند و اينك نيز به كار مى آيند.

\section{ب- (. كيمياترىى، فنّاورى شيميايى و دستَّاه تقطير در دوران اسلامى}

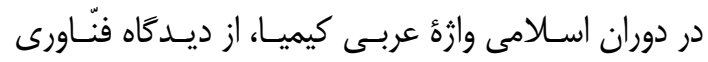

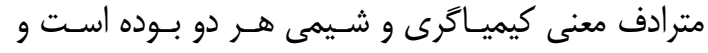

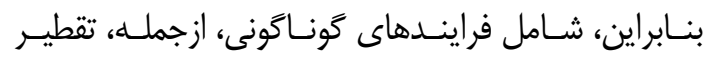

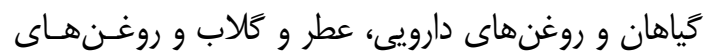

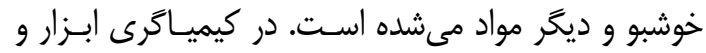

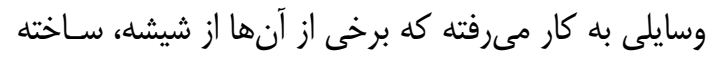

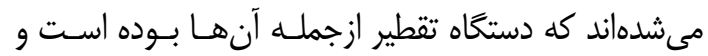
افرادى جون ابوموسى جابربنحيـان و ابـوبكر محمّــدبـن

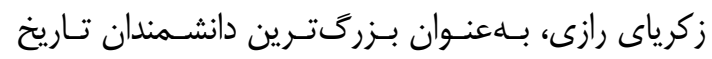

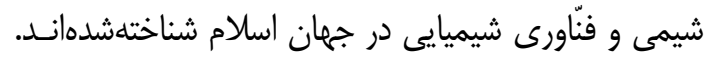

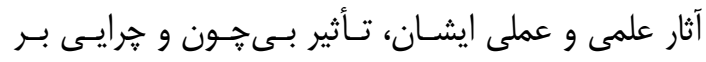

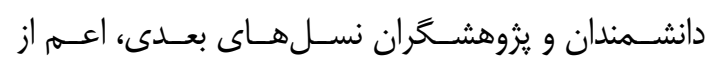

مسلمانان و ارويايىها، بر جاى كذاشته است [1] در فنّاورى شيميايى جهان اسلام كهـ تـدبير خوانسـان

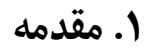

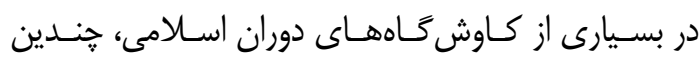

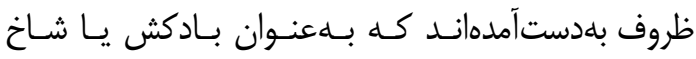
حجامت و انبيق، معرفى شدهاند. بادكش يا شـاخ حجامـت بـان در مصارف بهداشتى يا يزشكى كاربرد داشته است. انبيـق

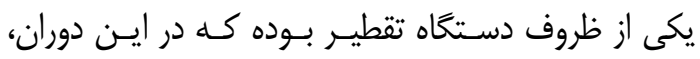

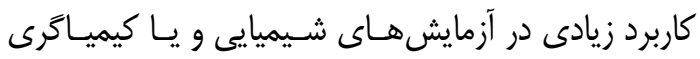

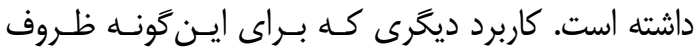

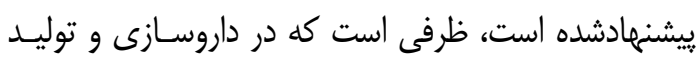

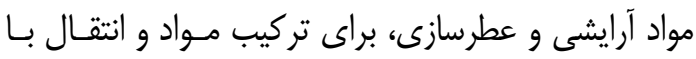

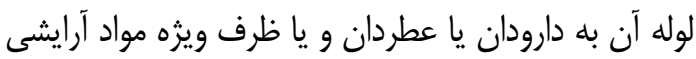

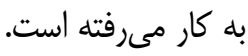
باوجود آن كه تعداد نمونههـاى مكشـوفه ازايـن كَونـهـ

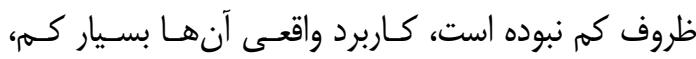

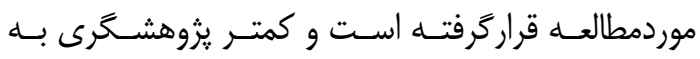
تجزيهوتحليل نهشتههاى احتمـالى درون آنهـا يرداختـهـ

$$
\text { است تا كاربرد آنها روشن شود. }
$$

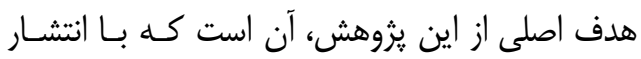

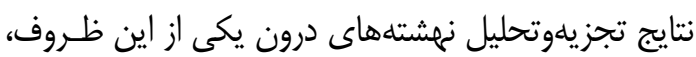

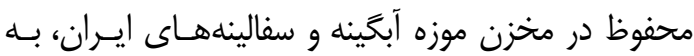

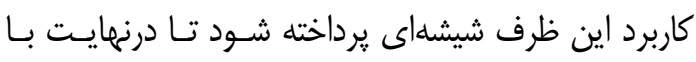

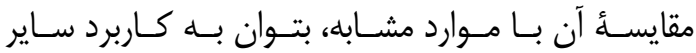

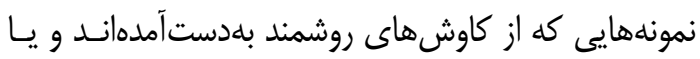

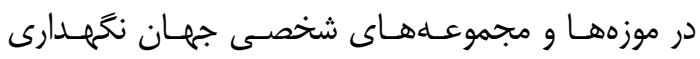

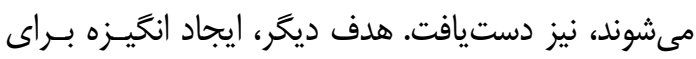

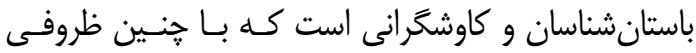

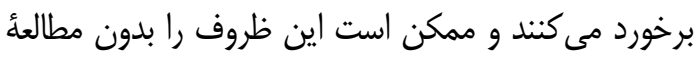

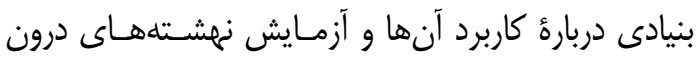
آنها به كنار نهاده باشند.

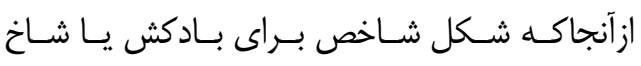

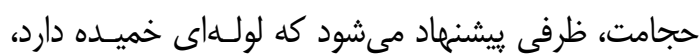
يرسش اصلى اين اسـت كـه كـاربرد ظـــف موردمطالعـاه،

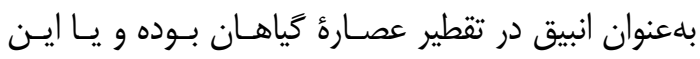

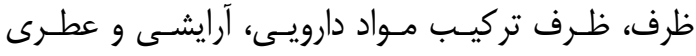

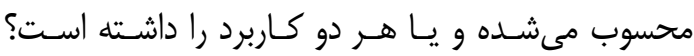
درصورتى كه كاربرد انبيق داشته، خه نوع مـوادى، در ايـن

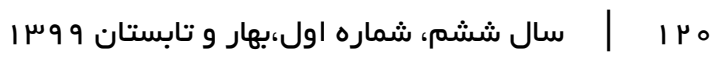


محل اتصال، حالت مورّب داشته و بلنداى بيشترى نسـبت

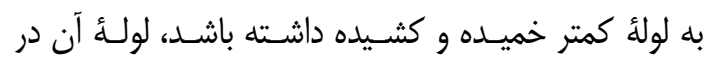

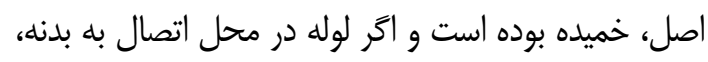

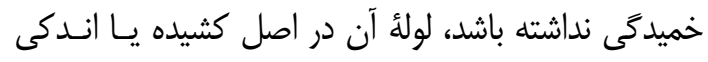

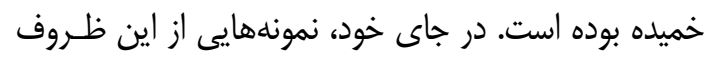

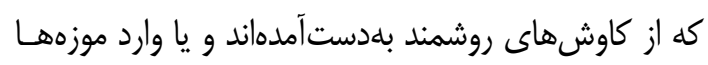

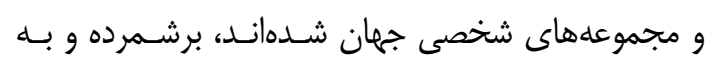

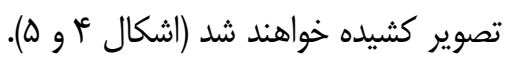

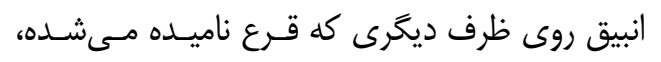

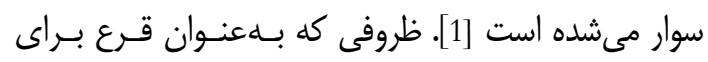

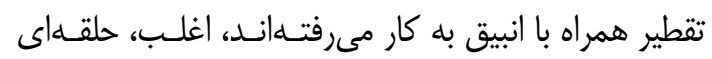

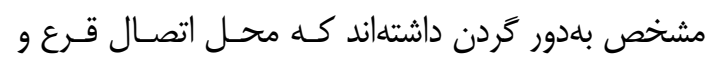

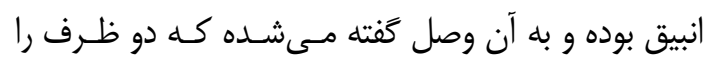
درون يكديخر جفت مىكرده است [3-11].

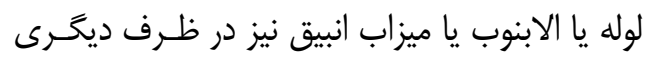

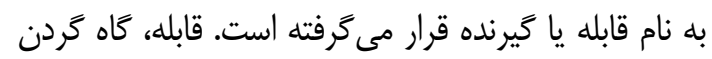

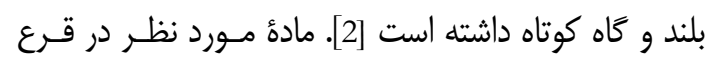

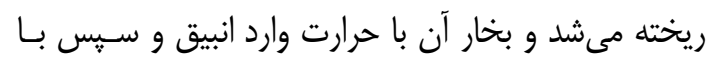

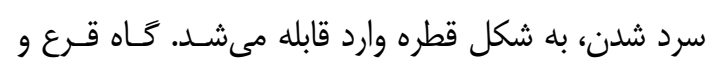

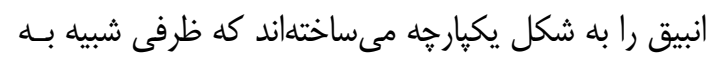

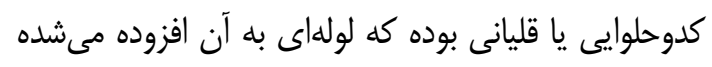

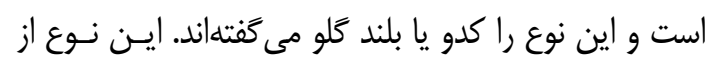

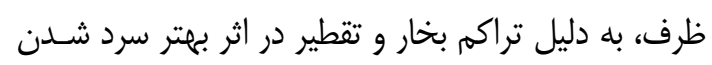

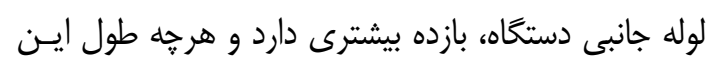

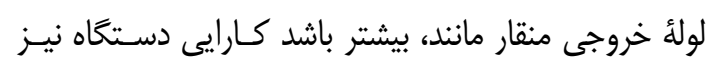
افزايش مى يابد [1,2].

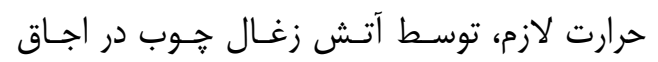

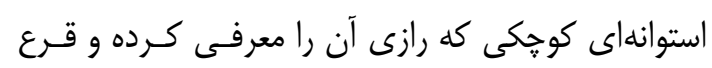

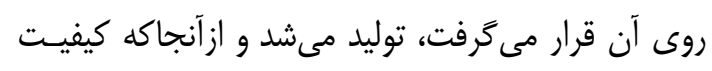

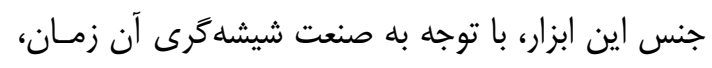

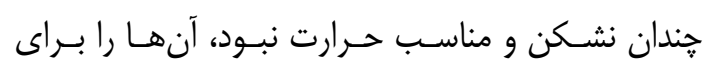

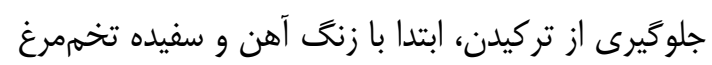

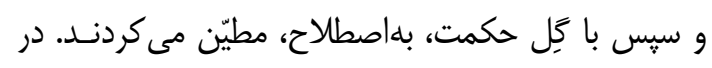

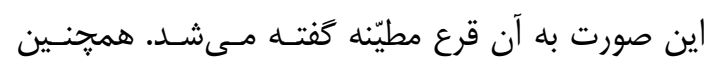

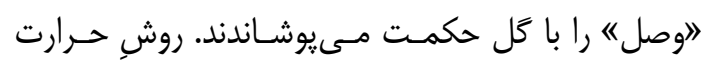

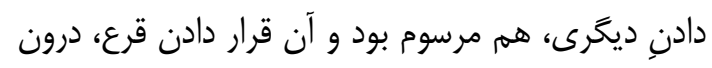

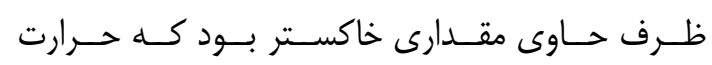

مىشد، تقطير يا فرو جاكانيدن، يكى از مهمترين فراينـدها

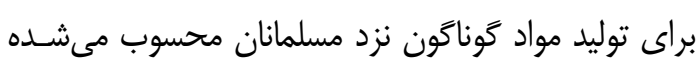

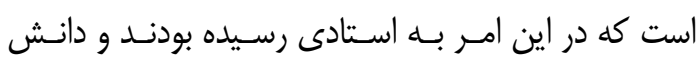

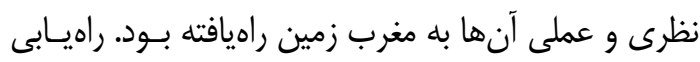

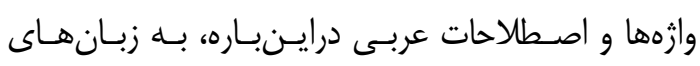

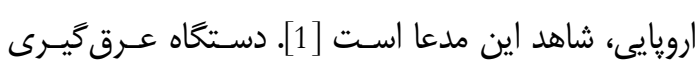

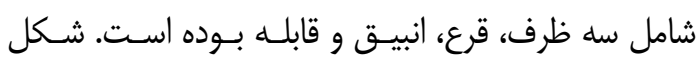

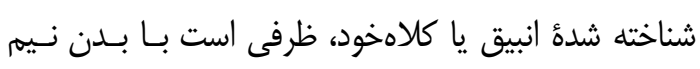
كروى، كف گرد يا مسطح و كردن كوتـاه و دهانـأَ نسـبتاً

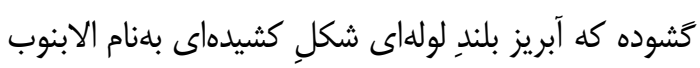

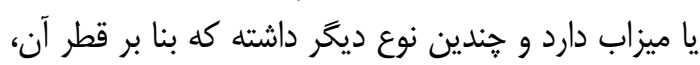

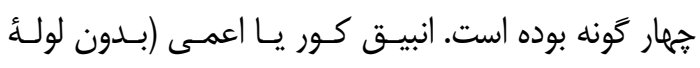

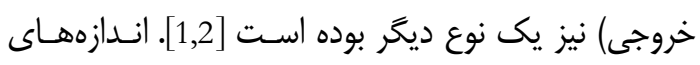

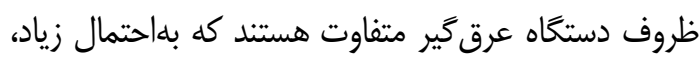

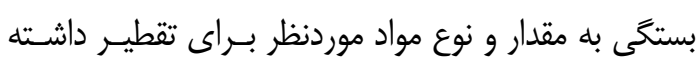

است (شكل ().

شكل ديخر انبيق كـه مـوردنظر ايـن نوشـتار اسـت،

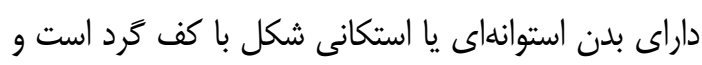

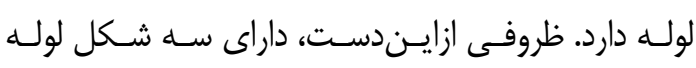

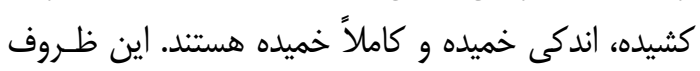

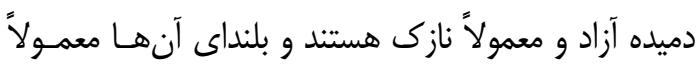

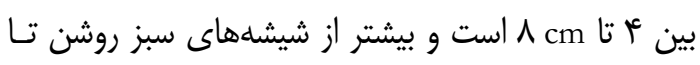

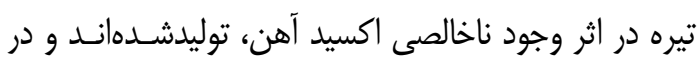

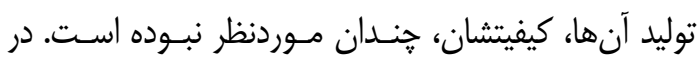

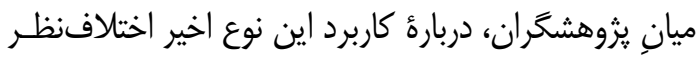

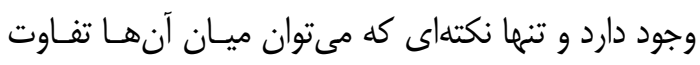

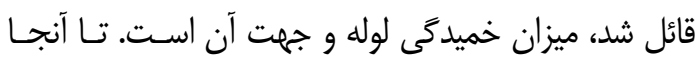

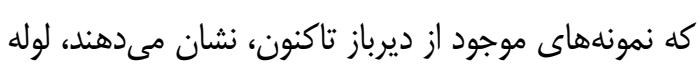

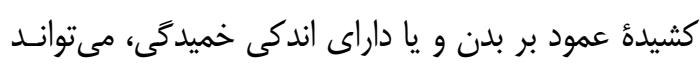

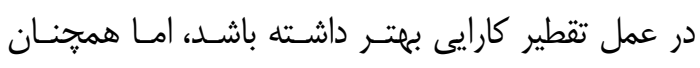
بلهعنوان بادكش يا شاخ حجامت نيز كارايى داشـته باشـــ

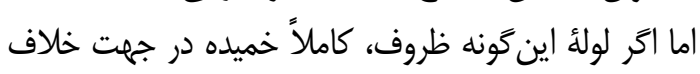

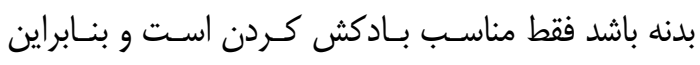

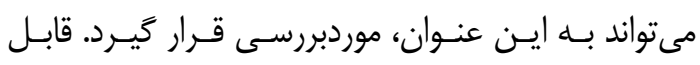

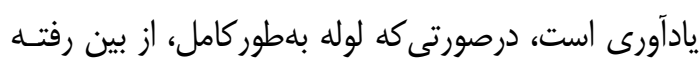

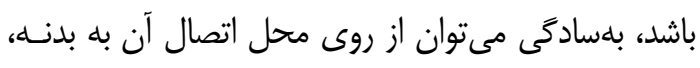

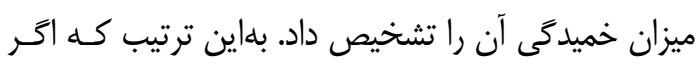


تاريخ سدههاى ع تا و ه.ق، دادهشده است، دستخاه كامـل،

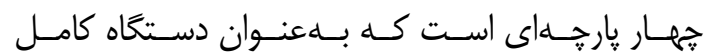

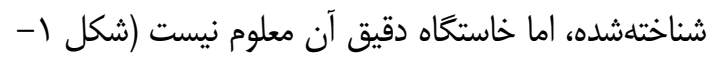

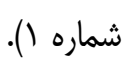

آتش بلهورت يكنواخت و تدريجى بلهقرع مىرسـيد [2].

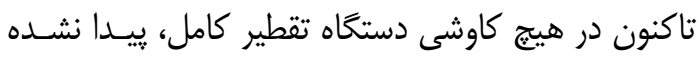
است. اما يك نمونه، در موزه علم لندن وجود دارد كه به آن

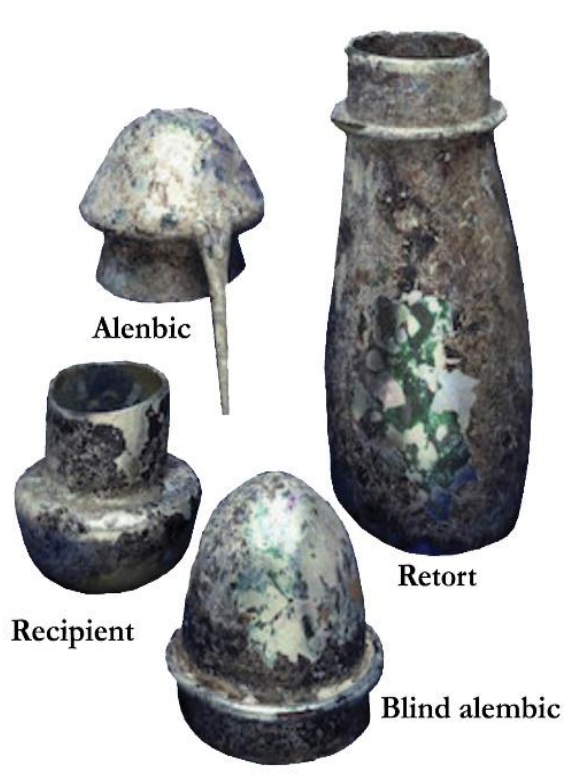

$\underline{1}$

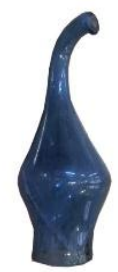

$\underline{5}$
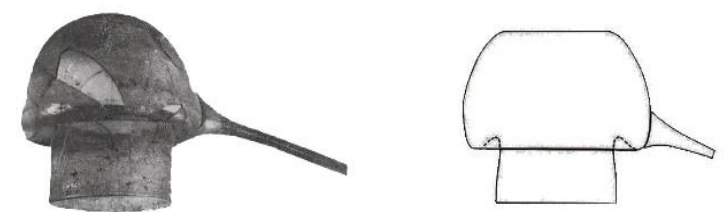

$\underline{2}$

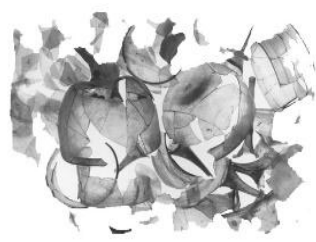

$\underline{3}$
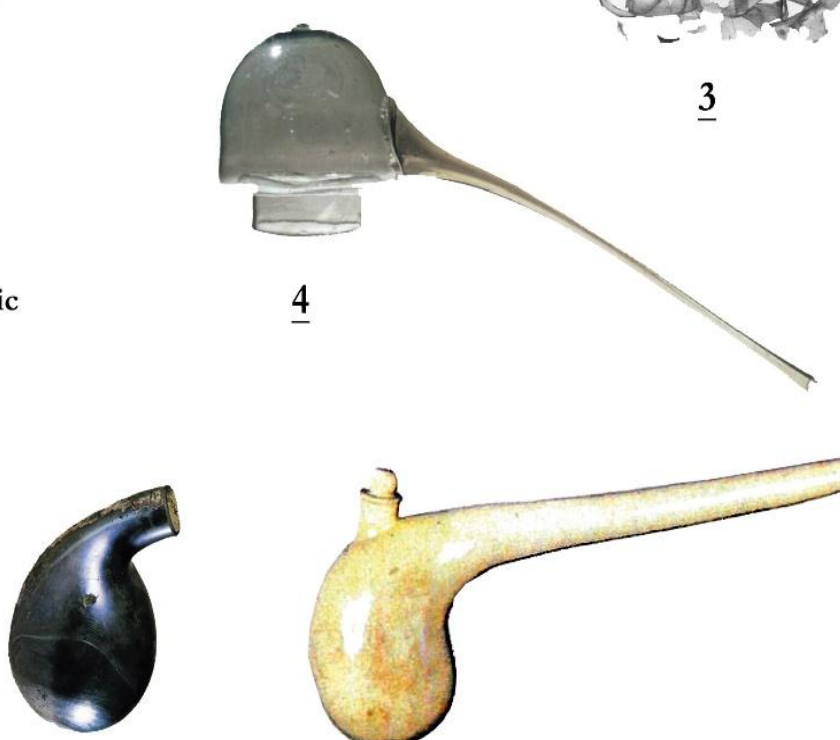

$\underline{6}$

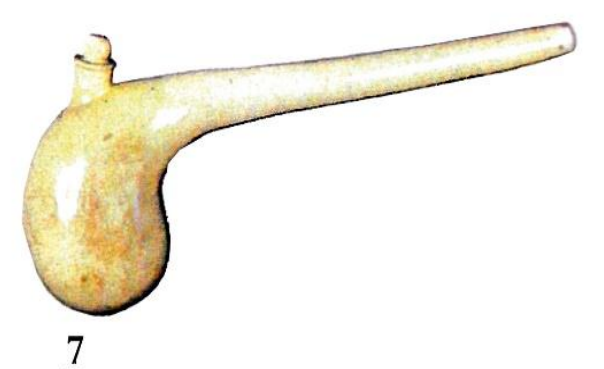

$\underline{7}$

شكل ا: ظروف تقطير دوران اسلامى تا معاصر

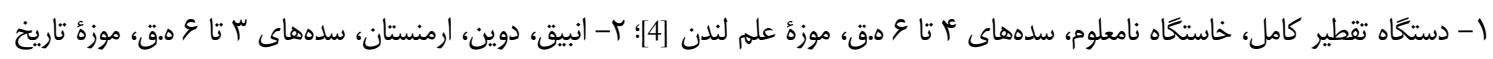

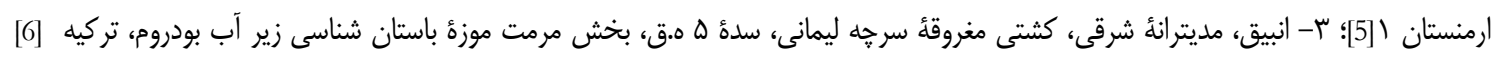
؛(337-1900)

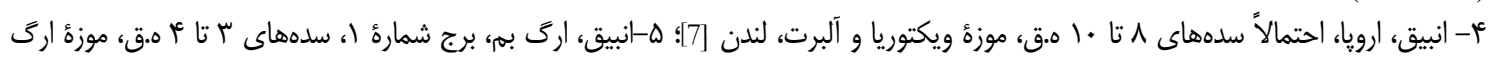

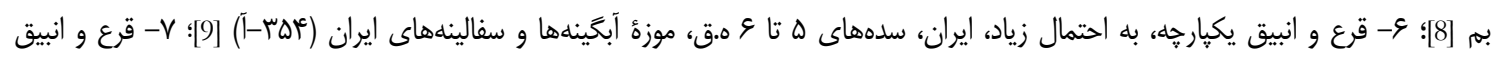

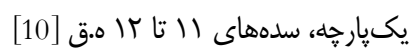

Fig.1: Several Islamic and contemporary distillation containers

1-A complete Distillation apparatuses, Unknown provenance, 10th-12th-centuries AD, Science Museum, London [4]; 2Alembic, Dwin, Armenia, 9th-12th-centuries AD, History Museum of Armenia [5]; 3- Alembic, East Mediterranean, serçe Limani shipwreck, 11th-century AD, conservation laboratory in the Bodrum Museum of Underwater Archaeology [6]; 4Alembic, Europe, 2th-4th-centuries AD?, Victoria \& Albert Museum (337-1900) [7]; 5- Alembic, Bam Citadel, Tower No.1, 9th-10th-centuries AD, Bam Citadel Museum [8]; 6- Retort, Iran?, 11th-12th-centuries AD, Glassware \& Ceramic Museum of Iran [9]; 7- Retort, 18th-century AD, the British Library [10] 
تصوير كشيده شده است (شكل r: شماره ع). در نوشتهاى به زبان سريانى و عربى از سده دهم ه.ق كه در كتابخانسٔ.

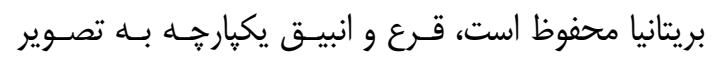

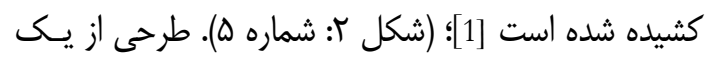

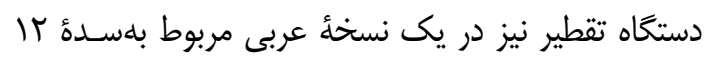

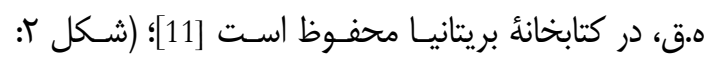

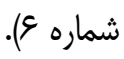
هانساى وولف از سالهاى آغازين سـده شمسى در

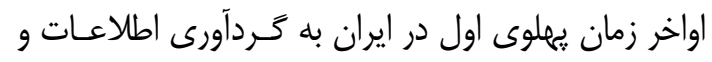

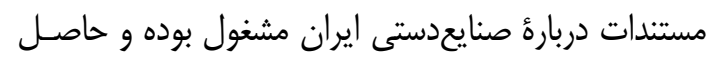

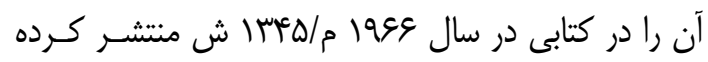

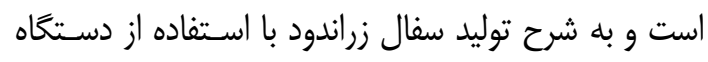

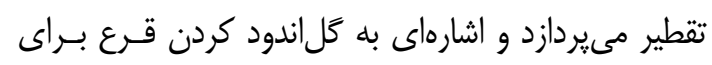

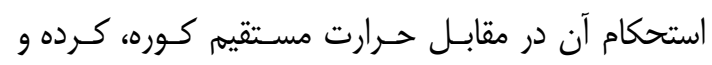

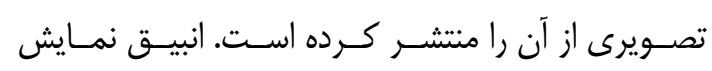
دادهشه، شكلى كروى با لولأ بسيار بلند و كشيده دارد كه إنه

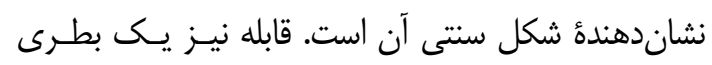

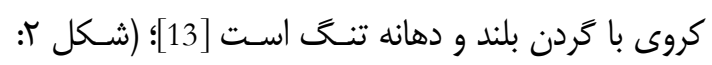

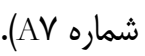
همجِنين سيد حسين نصر در كتابى كـه بـراى مـوزهُ

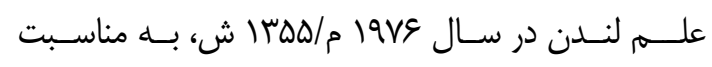

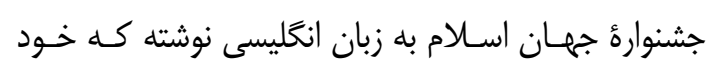

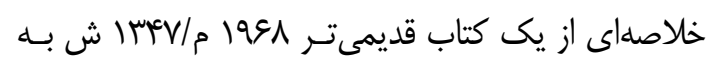

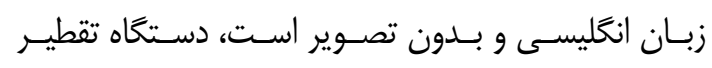

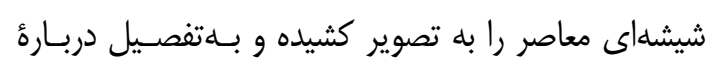

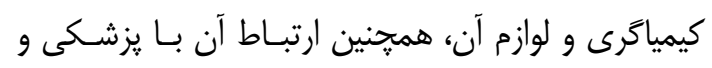

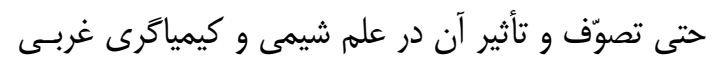

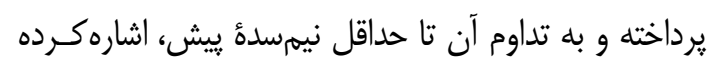
است [10,14]؛ (شكل ז: شماره BV).

\section{ץ-"ץ. شاخ حجامت يا بادكث}

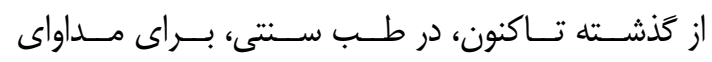

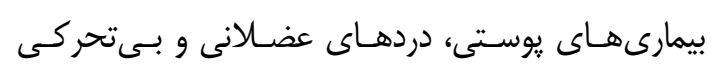

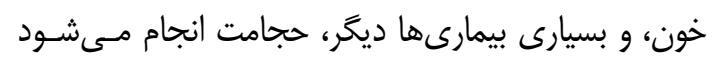

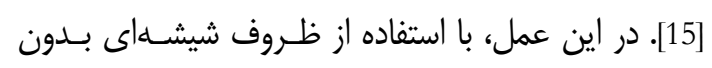

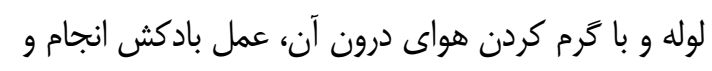

\section{ץ-r. دستخاه تقطير و عرق تَير شيشهاى بد روايت متون دوران اسلامى و معاصر}

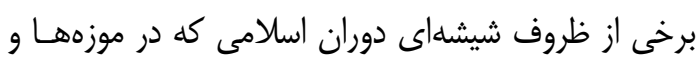

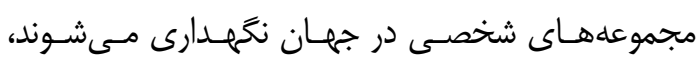

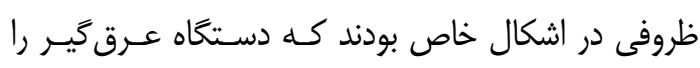

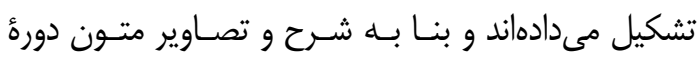
اسلامى مى توان آنها را بازشناخت.

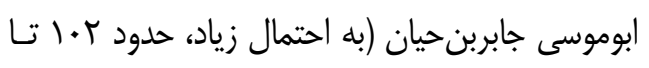

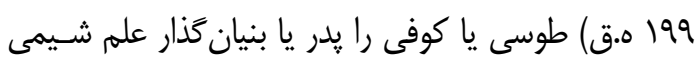

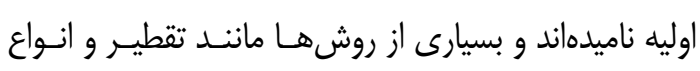

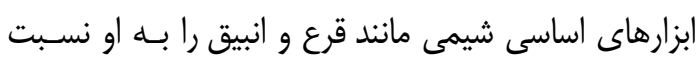

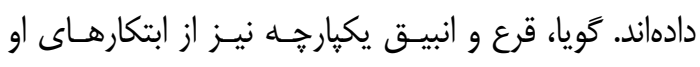

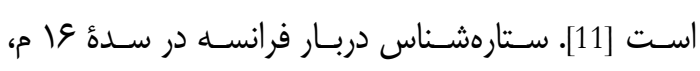

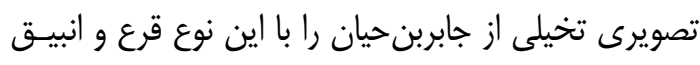

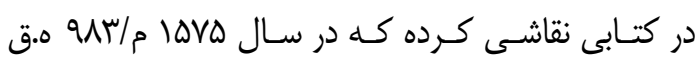

منتشرشده است [12]؛ (شكل ז: شماره () ). ابويوسف يعقوب ابن اسحاق كُندى دانشمند مشهـهور

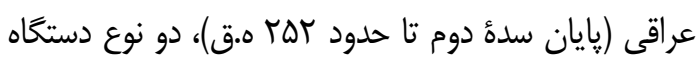

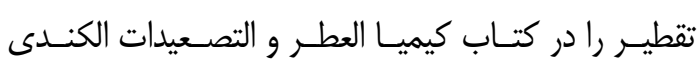

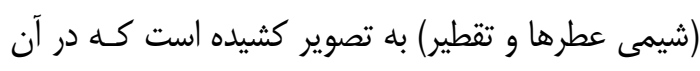

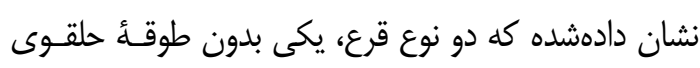

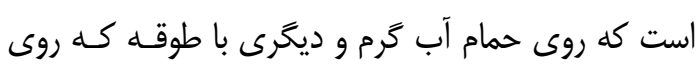
اجاق زغال جوب حرارت مى ديده است (شـكل ك: شـماره

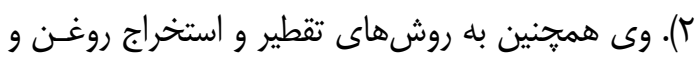

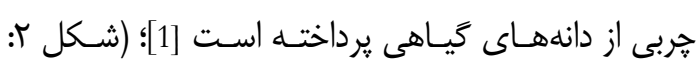
شماره بَ).

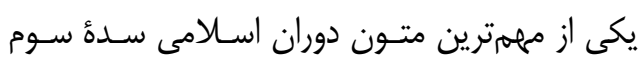
ه.ق، كتاب الاسرار يا رازهاى صنعت كيميا، نوشتهُ زكرياى دورئ

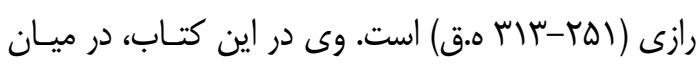

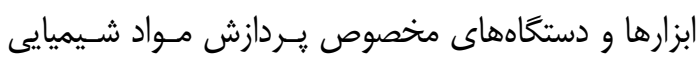

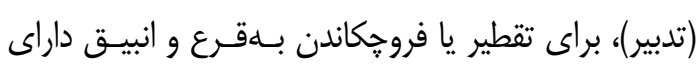
لولهُ خروجى، ظرف مايع تقطيرشده (قابله) و انبيق كور يـا اعمى (بدون لوله خروجى) يرداخته است [1,2].

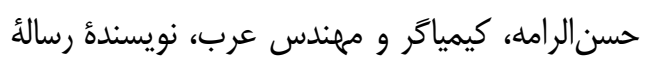

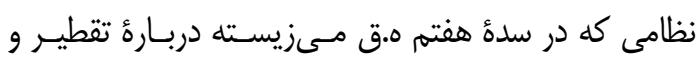
جداسازى اسانسهاى طبيعى نوشته و اين دسـتخاه را بــــ 


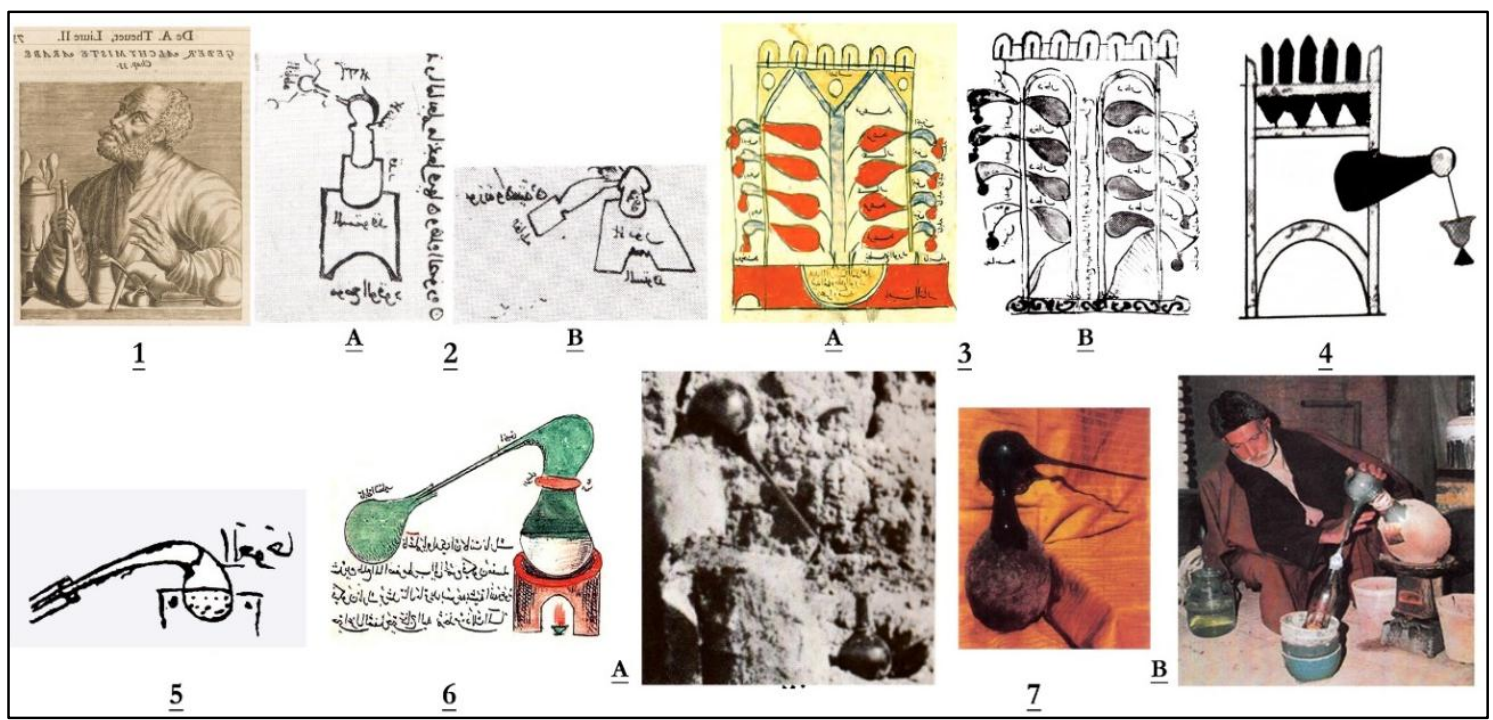

شكل ז: خند نوع دستخاه تقطير به روايت متون دوران اسلامى و معاصر

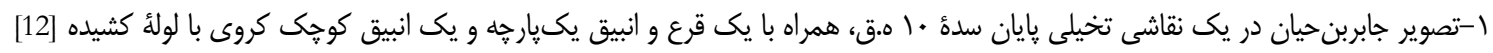

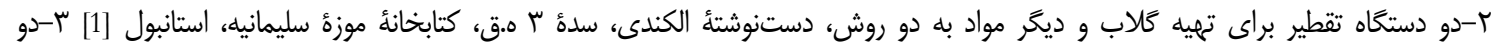

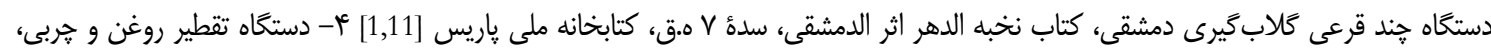

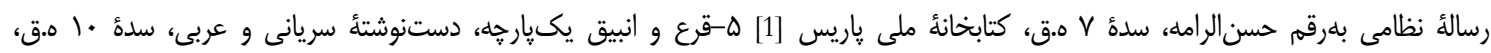

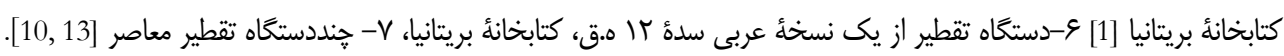

Fig. 2: Several types of Distillation apparatuses according to Islamic and contemporary texts

1- The image of Jaber Ibn Hayyan in a fictional painting from the end of the 4th century AD, with a Retort and a small spherical Alembic with a straight tube [12]; 2- Two distillers for rose water and other ingredients in two methods, Written by al-Kindi, 9th-century AD, Sulaimaniyah Museum Library, Istanbul [1]; 3- Two multi-retort rosewater distiller from Damascus, Book of Nokhbat al-Dahr, Written by al-Dameshghi, 13th-century AD, Paris National Library [1, 11]; 4- Oil and lipid distiller, Nezami's treatise, Written by Hasan al-Rammah, 13th-century AD, Paris National Library [1]; 5- Retort, illustrated in an Arabic and Syriac manuscript, 17th-century AD, the British Library [1]; 6- A distiller illustrated in an Arabic manuscript, 19th-century AD, the British Library [11]; 7- Several modern distillers [10, 13]

روى زمين نهاده شود، بلنـداى لولـه آن از بدنـه، بيشـتر

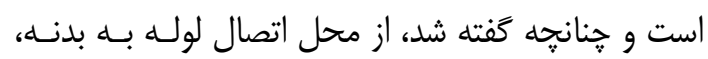

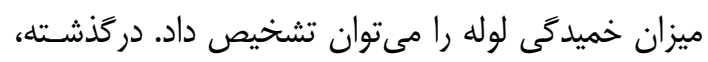

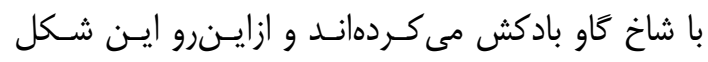

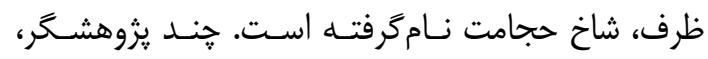

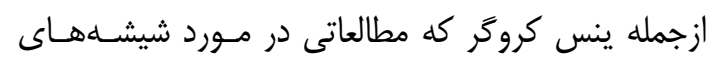

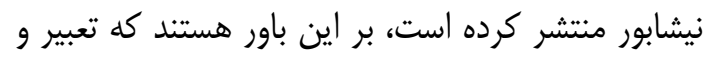

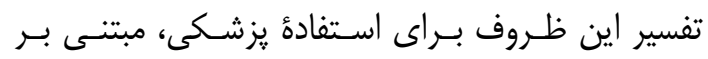
نغارهاى در مقامات حريرى است كه حكيمى را در حسال

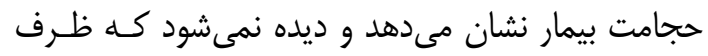

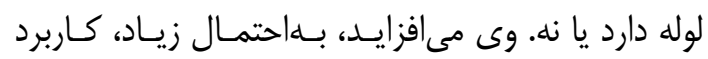

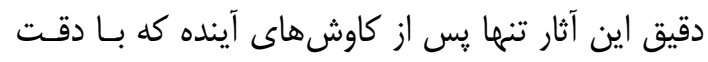

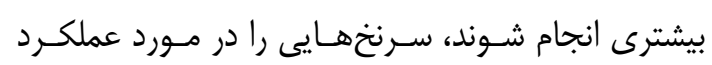

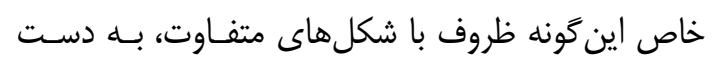

سيس محل بـادكش، بـا تيـخ خراشـيده و خــونَرفتـهـ

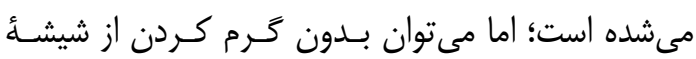

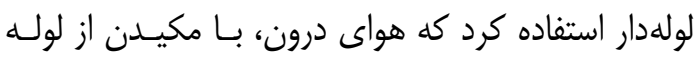
خارج مىشده است. دركذشته اين عمل را حجـامتخر يـا

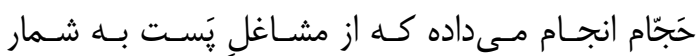

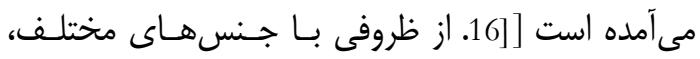

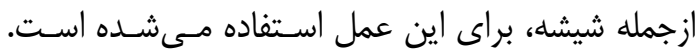

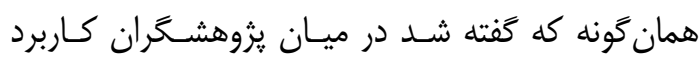

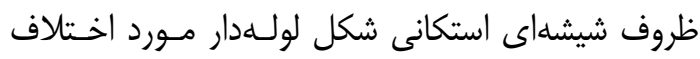
است. در تعريف بادكش يا شاخ حجامت شيشــانهاى بايسـ

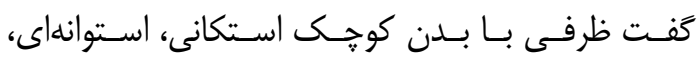
تخممرغى و يا كلابیىشكل است كه كفى كـرد و آبريـز

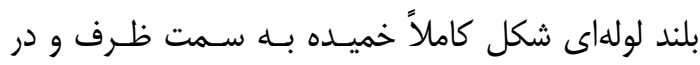
جهت مخالف با بدنه دارد و درصـورتى كـهـ از دهانـهـ بــر 
ملى ڤاريس و كتابخانه كاخموزه تويكايى هسـتند كـه در

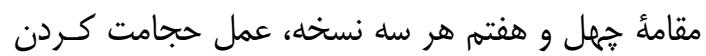

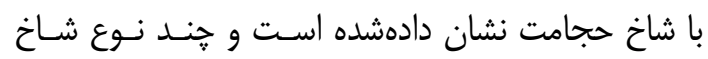

حجامت به تصوير كشيده شدهاند [21-17] (شكل بَ).
مى دهند [3]. بايد يادآور شد كه نسـخههـاى متعـددى از

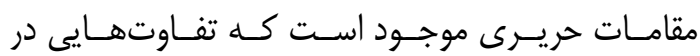
نقاشىهاى آنها وجود دارد. نفيسترين آنها سه سه نسخء

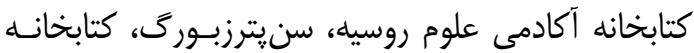

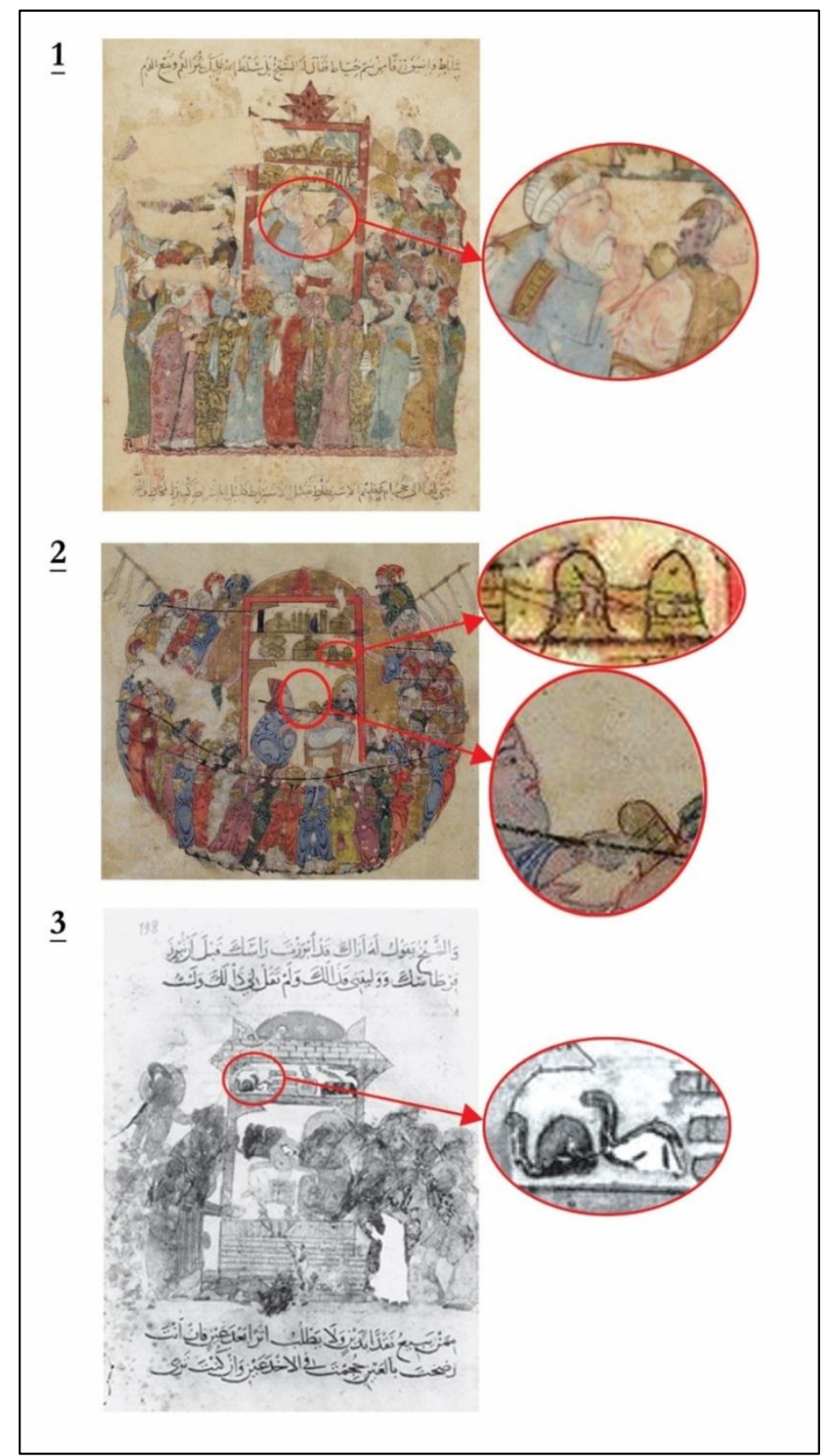

شكل س: تصوير شاخ حجامت و عمل حجامت در مقامٔ جِهل و هفتم مقامات حريرى

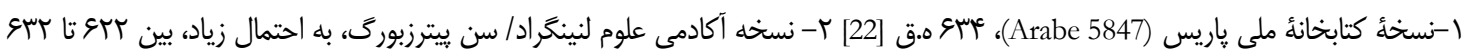

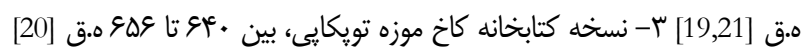

Fig. 3: Image of the cupping glass and phlebotomize in the forty-seventh Maqama of Maqamat al-Hariri 1-Manuscript of Paris National Library(Arabe 5847), 1237 AD [22]; 2-Manuscript of Leningrad Academy of Sciences / St. Petersburg(s23), 1225-1235 AD? [19,21]; 3-Manuscript of Topkap1 Palace Museum Library, (3493), 1242-1258 AD [20] 


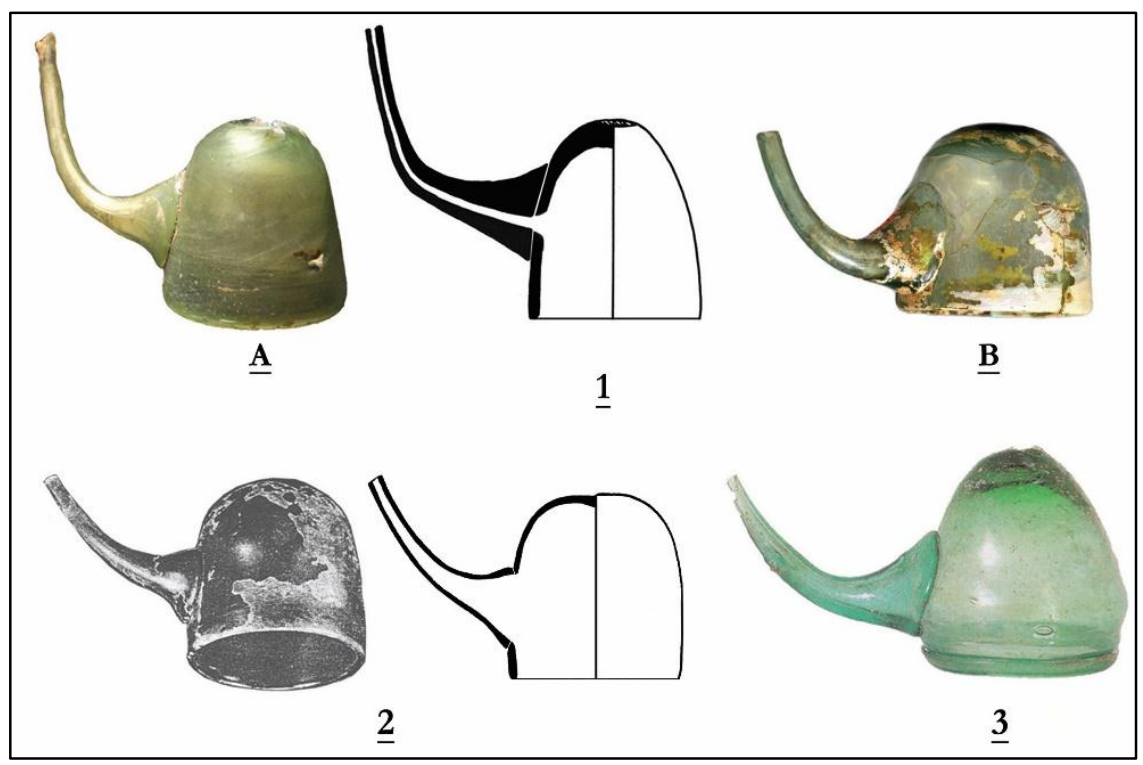

شكل ثا: خند بادكش يا شاخ حجامت شيشهاى با لوله خميده

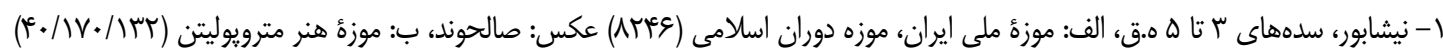

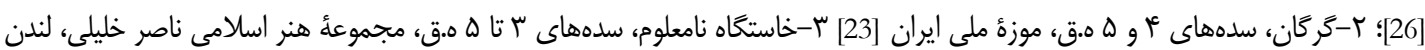

[16] GLS454))

Fig. 4: Several cupping glass with a curved tube

1-Neishabour, Sabz Pushan, 9th-11th centuries AD, A: National Museum of Iran, Islamic Period Museum (8246),B: Metropolitan Museum of Art (40.170.132) [26]; 2-Gorgan, 10th-11th centuries AD, National Museum of Iran [23]; 3- Unknown provenance, 9th-11th centuries AD, The Nasser D. Khalili Collection of Islamic Art, London (GLS454) [16]

فرضهايى هستند كه بـر اسـاس شـكل آنهـا بــوجــود آمدهاند.

نيثنابوز: سه نمونه از كاوشهاى نيشابور، يكى در مـوزء

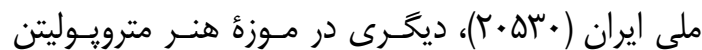

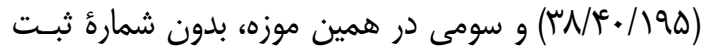

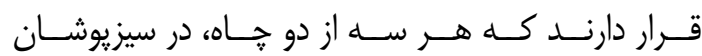
بلهدستآمدهاند، اين نمونهها لولههاى نسبتاً كشيده دارند و و براى انبيق بودن به نظر مناسبتر مىرسند. كروگر بر اين

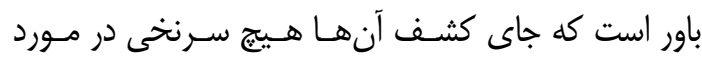
كاربرد اصلى آنها به دست نمـى بهـهـد، امـا كـاربرد سـاير ظروف نيشابور نشان مىدهند كه اين ظروف نيـز ممكـن

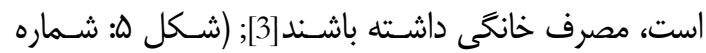
$\stackrel{r}{r}(1 \mathrm{~A}, \mathrm{C}$ كرَّان: دو ظرف از اين محوطه، مربوط به سدههاى أو ه ه.ق، شاخ حجامت معرفىشدهاند [23]. لولههاى اين دو،

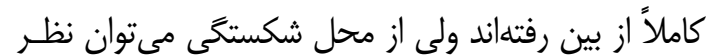

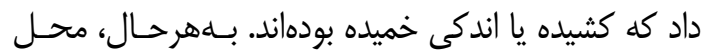

در اينجا براى مقايسُٔ ظاهرى، جند ظرف كه به دليل

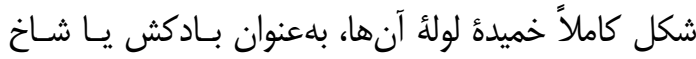
حجامت ييشنهلاد مىشوند، معرفى و تصوير مىشوند. ايـن ظـروف، در مــوزههـا و مجموعـهـهــاى شخصـى جهـان

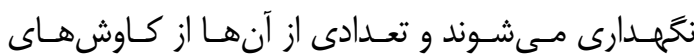

روشمند بلدستآمدهاند (شكل ع).

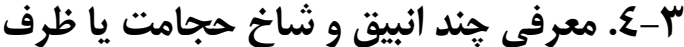

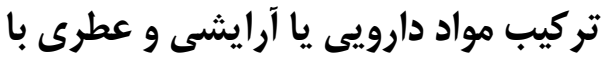 لولأ كشيده يا اندكى خميده}

در اين بخش، جند ظرف با شكل موردنظر و با لولـهـــاى

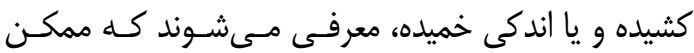
است هر سه كاربرد را داشته باشند. اين ظروف، همخَى از كاوشهاى روشمند در ايران بلدستآمدهاند و هيج كدام از

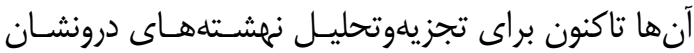
مورد بررسى قرار نخرفتهاند و ييشنهاد كاربردهاى مختلفى تهري

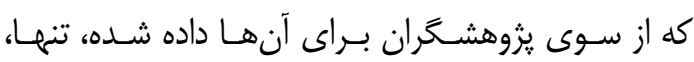

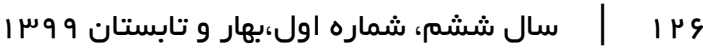


مشترك ايران و ايتاليا در برج شمارهُ ا ارك بمه، قطعاتى از ظروف لولهدار بهدستآمدهاند كه با داشتن لوله آلهاى كثيده

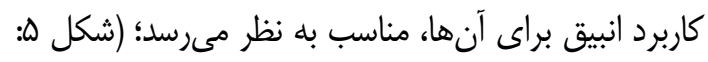

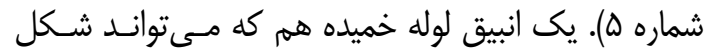

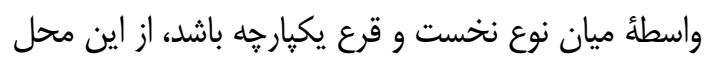
بهدست آمده است [8]؛ (شكل (: شماره هان).

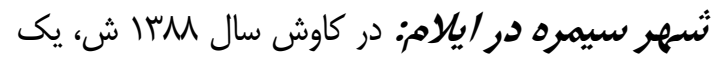

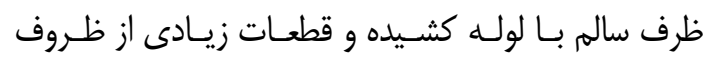
مشابه، بهدست آمداند [30].

\section{س-ه. ظرف تر كيب مواد دارويى يا آرايشى و}

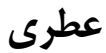

ظرفى كه در داروسازى و توليد مواد آرايشى و عطرسـازى

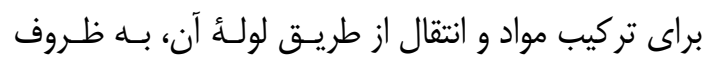
مربوطه به كار مىرفته است، شايد، ظرفى مشـابه آنجـهـ

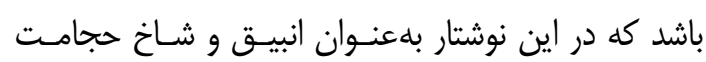

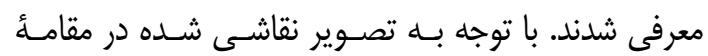

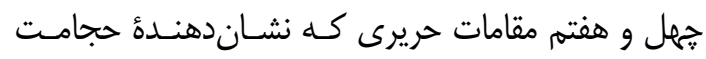

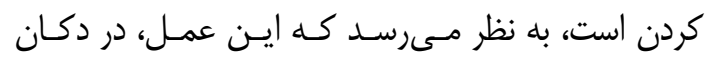

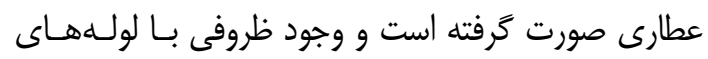

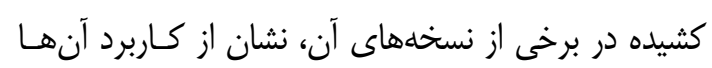

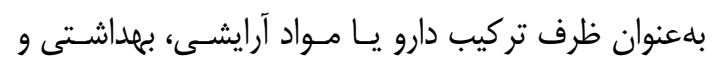
عطر دارد [16]؛ (شكل ه).

\section{ع. مواد و روشها}

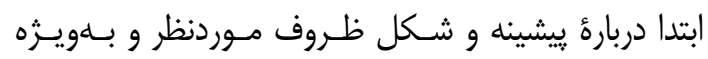

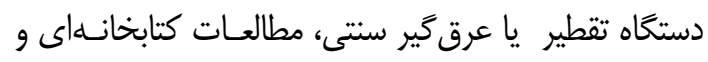

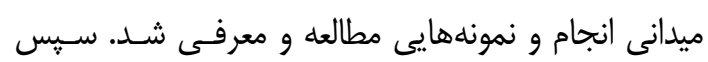

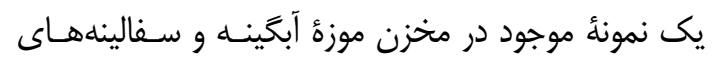

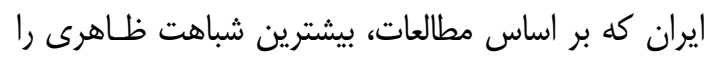

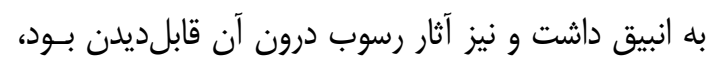

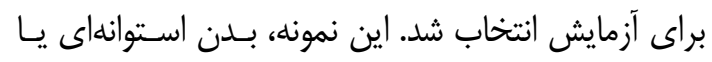

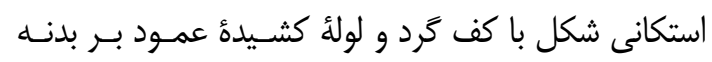

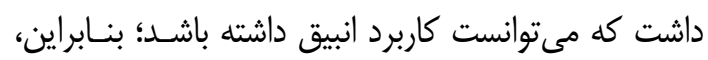

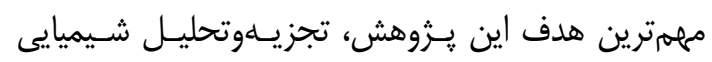
نهشتهاى درون اين ظرف شيشهاى بود كه براى رسيدن

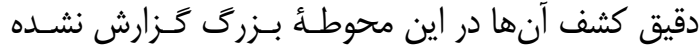

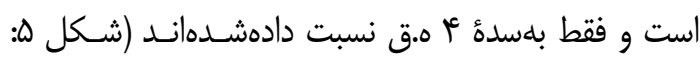
شماره r. r. r ثوث: از كاوشهاى ديولافوآ، دو موركَان و دومكـنه،

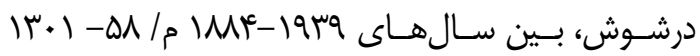

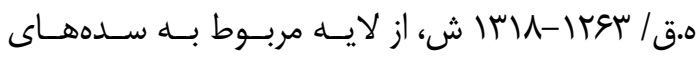

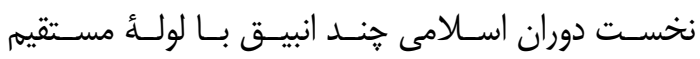

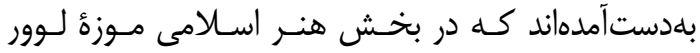

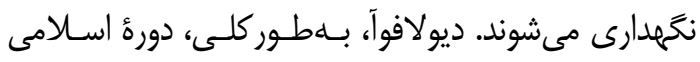
شوش و ظروف شيشهاى مكشوفه از آن را به سـال دهاى دورئ

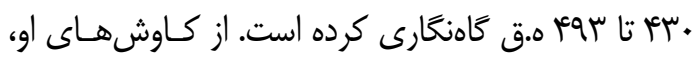

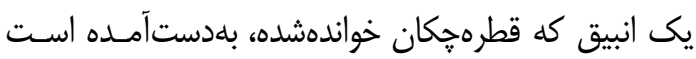

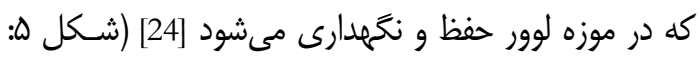
3A ). لام، ضمن كاهنخارى شيشههاى اسلامى مكشوفه از

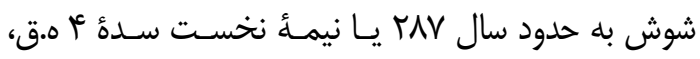

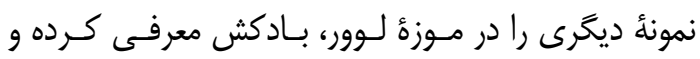

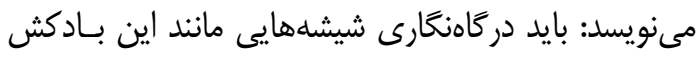

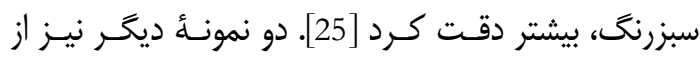

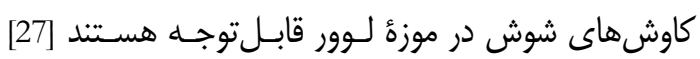
(شكل ه: شماره 3B,C). در سال 1909 م/ אبrا ش، در زمان كاوشها.

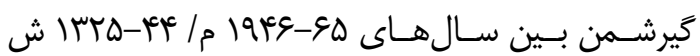

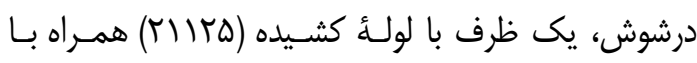

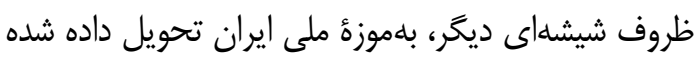

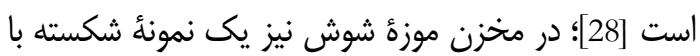
لولأ كشيده، محفوظ است.

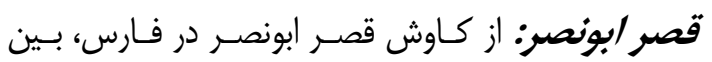

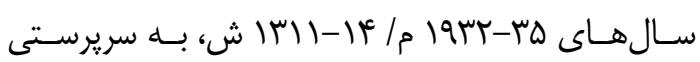

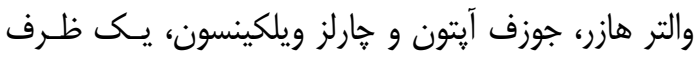

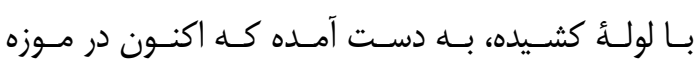

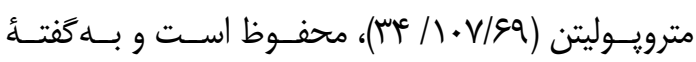

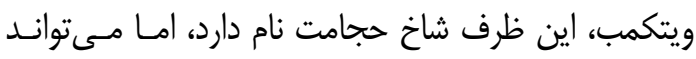

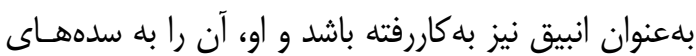

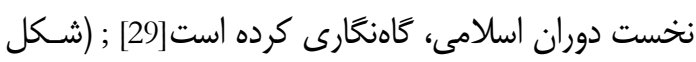

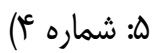

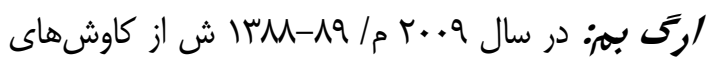




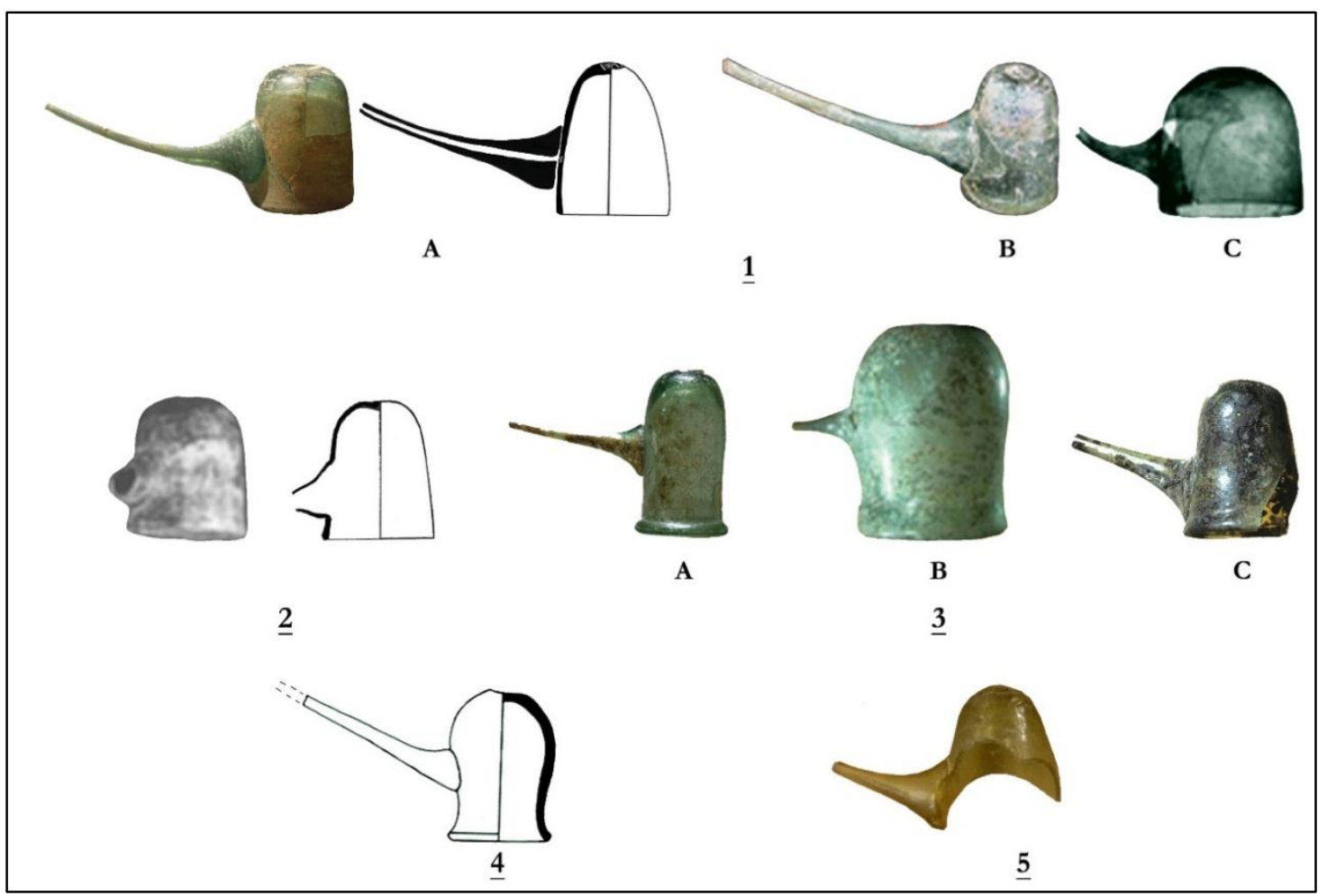

شكل ه: انبيق و شاخ حجامت يا ظرف تركيب مواد دارويى يا آرايشى يا عطرى با لولأ كشيده يا اندكى خميده

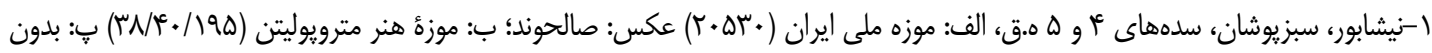

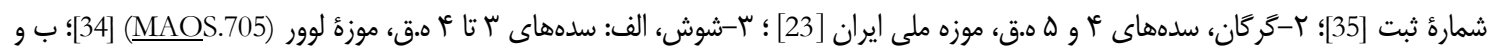

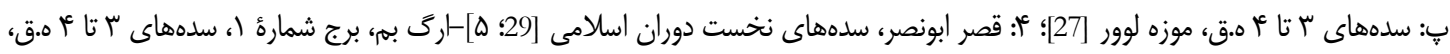

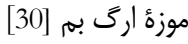

Fig. 5: Alembic and cupping glass or container for composition of medicine and cosmetics and perfumes, with stretched or slightly curved tube

1-Neishabour, Sabz Pushan, 10th-11th centuries AD, A: National Museum of Iran (20530), B-C: Metropolitan Museum of Art (38.40.195)\& No registration number [26]; 2-Gorgan, 10th-11th centuries AD, National Museum of Iran [23]; 3-Susa, A: B-C: 9th-10th centuries AD, Louvre Museum [31]; 4-Qast-i Abu Nasr, 9th-10th centuries AD, Louvre Museum(MAOS.705), Early Islamic Period [29]; 5-Bam Citadel, Tower No.1, 9th-10th centuries AD, Bam Citadel Museum [30]

باريك با كف گرد است؛ يك لوله كوتاه كشيدة عمـود بـر بدنه دارد و بلششماره

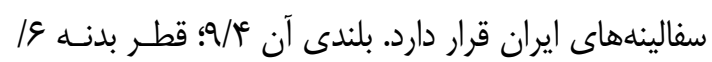

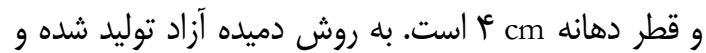

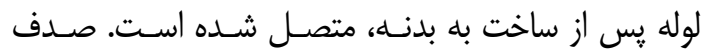

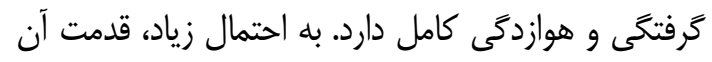

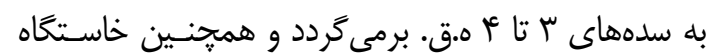

$$
\text { آن نامشخص است (شكل ع). }
$$$$
\text { ع-r. روش بروسى }
$$

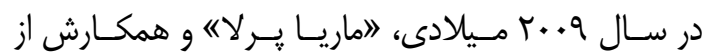

به جنبئ كاربردى آن، صورت گرفت. در اين راستا،

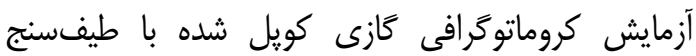

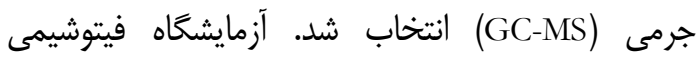

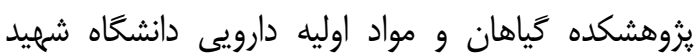
بهشتى بهترين زَينه در بين آزمايشگاهها بود؛ بنابراين با

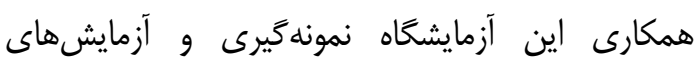

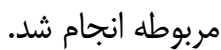

ع-1 ـ مشختصات نمونهُ مورد آزمايث

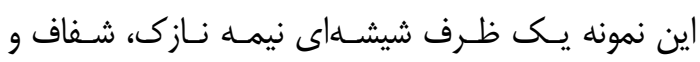
بىرنگ با سايه زرد (نباتى) با بدن اسـتكانى شـكل ميـان

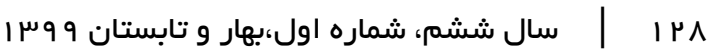


آزمايش، بهآزمايشكاه منتقل شود. يادآور مى شـود محلـول

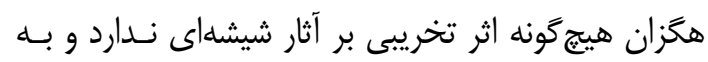

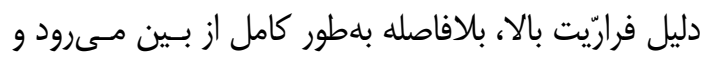

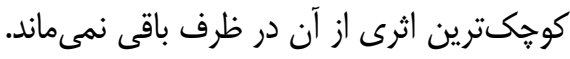

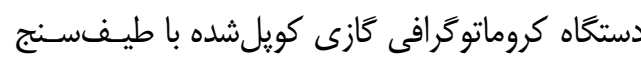

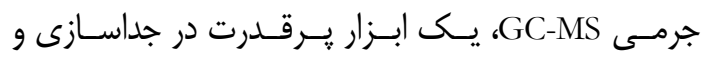

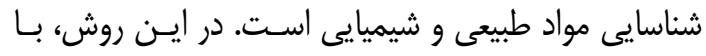

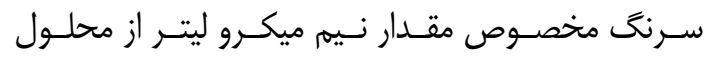

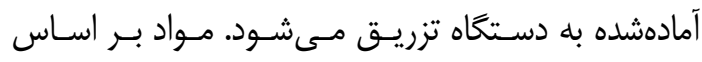

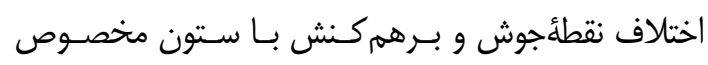

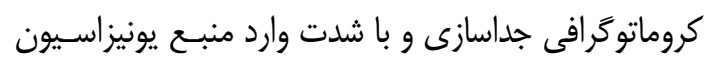

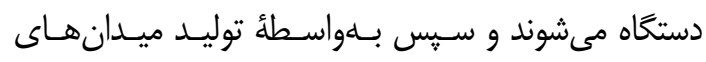

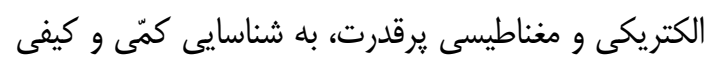

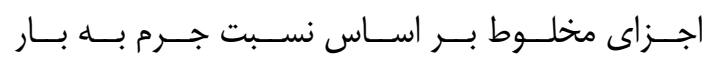

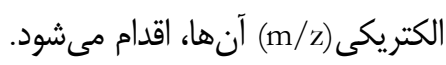

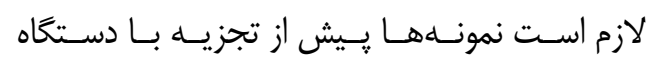

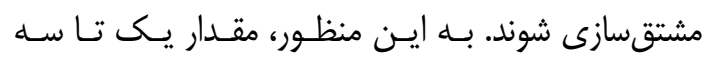

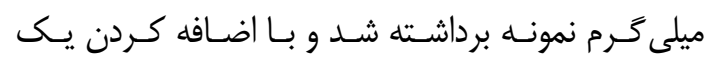

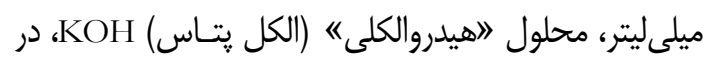

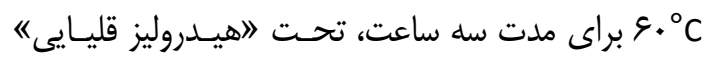

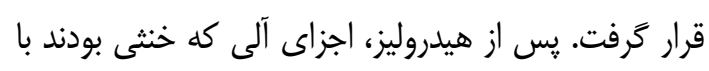

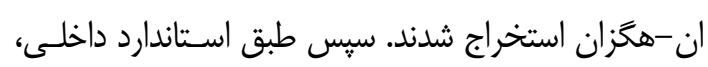

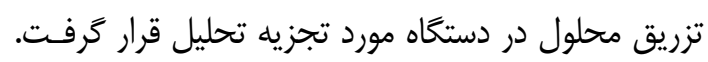

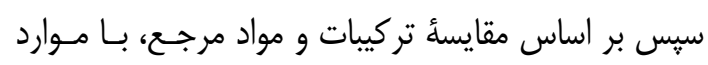

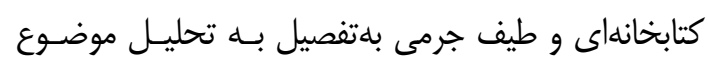

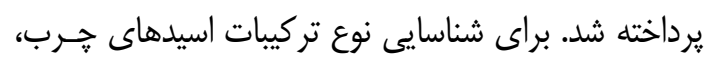

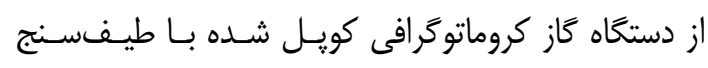

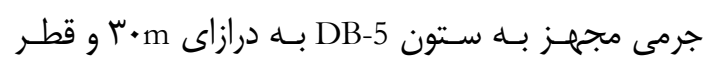

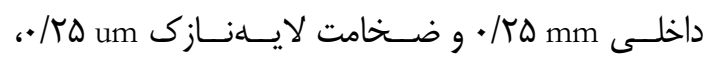

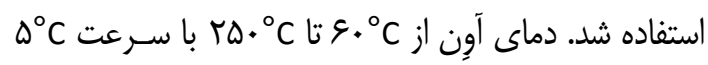

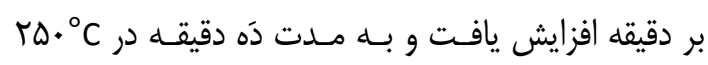

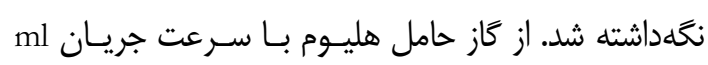

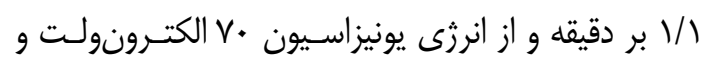

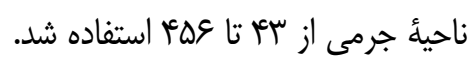
تجزيهوتحليل اطلاعات با استفاده از روش يادشـاده،

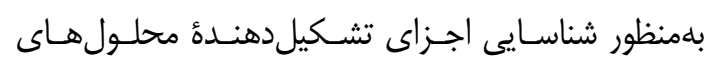
بددستآمده از ظرف موردمطالعه، صورت كَرفت. شناسيايى

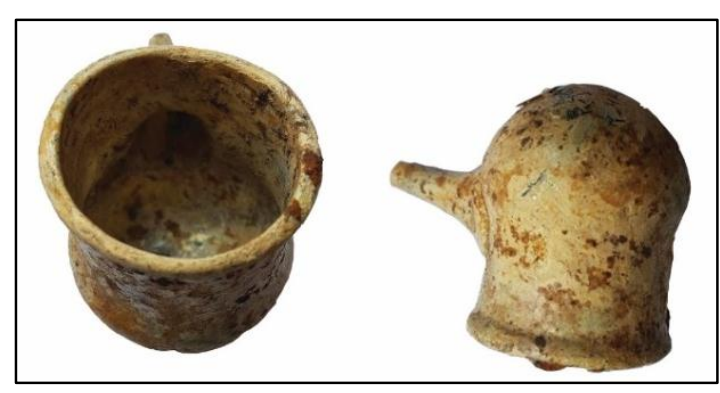

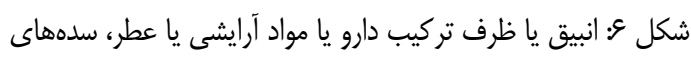

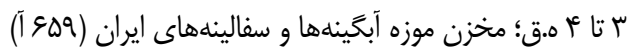

Fig. 6: Alembic or container for composition of medicine and cosmetics and perfumes, 9th-10th centuries AD,

Reservoir of Glassware \& Ceramic Museum of Iran (659)

دانشخاه بيزاى ايتاليا در كتاب طيفسنجى جرمى مواد آلى كرئ

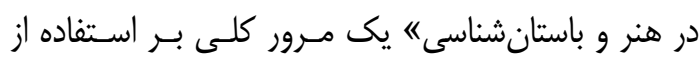

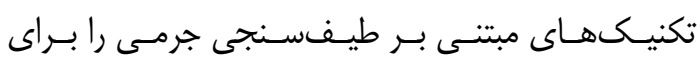

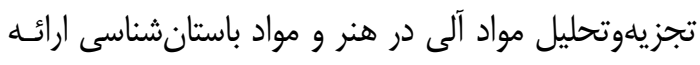

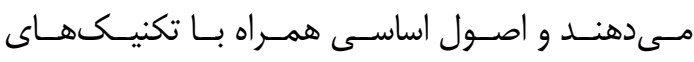

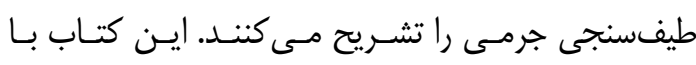

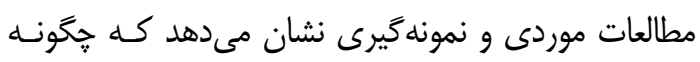

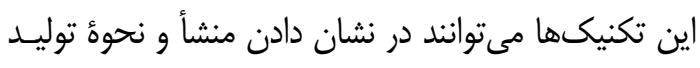

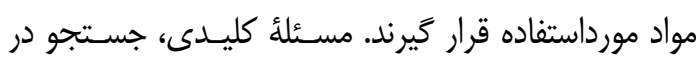

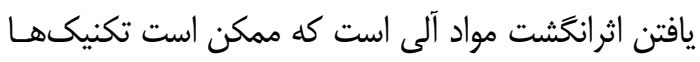

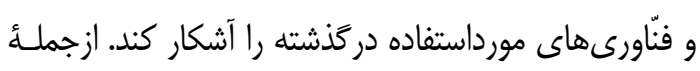

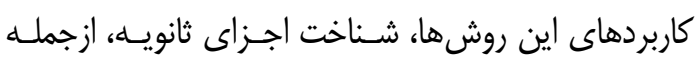

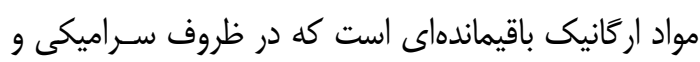
شيشه يافت مىشود [32].

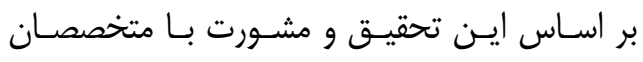

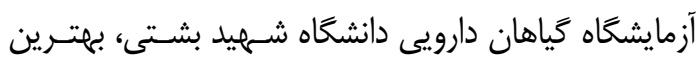

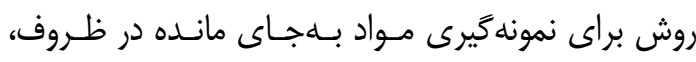

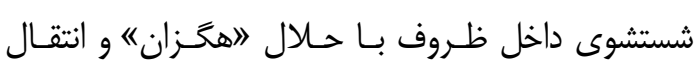

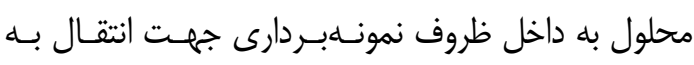

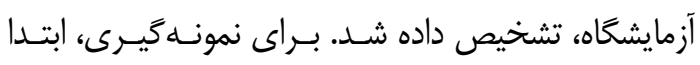

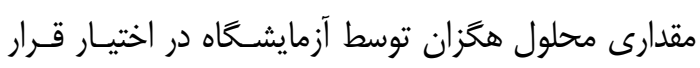

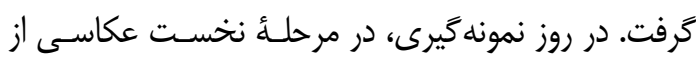

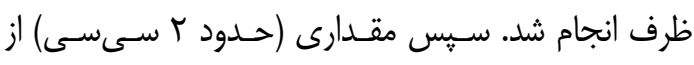

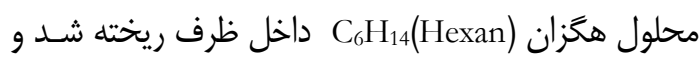

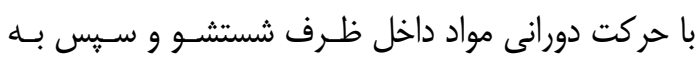

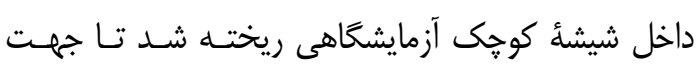


0. نتايج و يافتهها ه- ا. تر كيبات شيميايى شناسايیى شدهد در

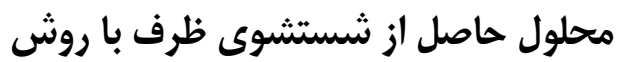
GC-MS تجزئُ محلول حاصل، منجر به شناسايى بيست و دو ماده،

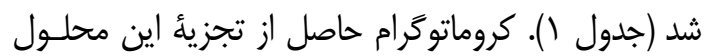

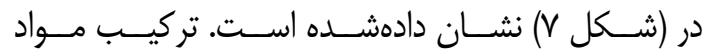

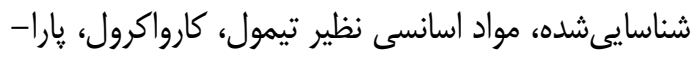

تركيبات با استفاده از يارامترهاى مختلـف از قبيـل زمـانِ

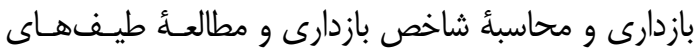

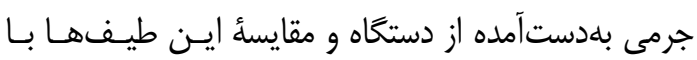

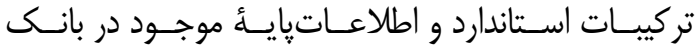
اطلاعاتى GC-MS، توسط نرمافزار كنترل كنتــدهُ دسـتخاه

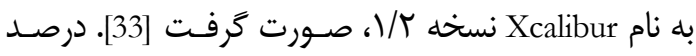
نسبى هر كدام از تركيبات تشكيل دهندة اسانس با توجه به به

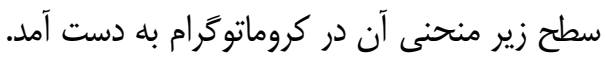

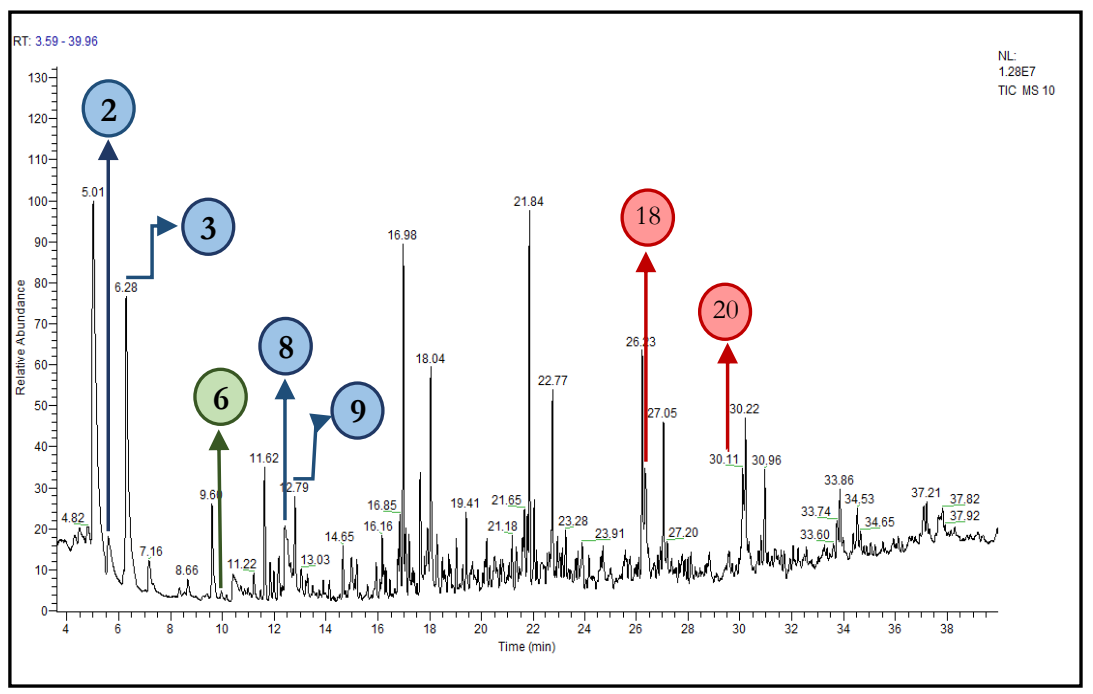

شكل V: كروماتوكرام GC-MS حاصل از تجزيه مواد موجود در ظرف

Fig.7: The GC-MS chromatogram of analysis the solution resulted from sediments in the glass container

جدول ا: تركيبات شناسايىشده در نهشتههاى ظرف موردمطالعه

Table 1: The chemical composition of solution extracted from sediment of the glass container

\begin{tabular}{|l|l|c|c|c|}
\hline No & Components & Retention time(min) & Retention index & Composition (\%) \\
\hline 1 & Nonane & 5.01 & 900 & 24.46 \\
\hline 2 & p-Cymene & 5.59 & 1020 & 3.51 \\
\hline 3 & $\gamma$-Terpinene & 6.28 & 1051 & 10.96 \\
\hline 4 & Undecane & 7.16 & 1100 & 2.84 \\
\hline 5 & Dodecane & 9.06 & 1200 & 1.77 \\
\hline 6 & Salicylaldehyde & 10.4 & 1250 & 2.9 \\
\hline 7 & Tridecane & 11.62 & 1298 & 2.32 \\
\hline 8 & Thymol & 12.41 & 1305 & 4.55 \\
\hline 9 & Carvacrol & 12.79 & 1310 & 1.21 \\
\hline 10 & Tetradecane & 14.65 & 1400 & 1.03 \\
\hline 11 & Pentadecane & 16.98 & 1500 & 5.89 \\
\hline 12 & 3,5-Di-tert-butylphenol & 17.63 & 1520 & 2.59 \\
\hline 13 & Hexacosane & 18.04 & 1600 & 3.95 \\
\hline 14 & Phytane & 21.84 & 1706 & 6.22 \\
\hline 15 & Octacosane & 22.03 & 1800 & 1.1 \\
\hline 16 & Nonacosane & 22.77 & 1900 & 3.59 \\
\hline 17 & Docosane & 26.23 & 1998 & 4.51 \\
\hline 18 & Palmitic acid & 26.34 & 2010 & 3.13 \\
\hline 19 & 2-methyl-docosane & 27.05 & 2020 & 2.54 \\
\hline 20 & Steraic acid & 30.11 & 2120 & 2.22 \\
\hline 21 & 2-Methyl-eicosane & 30.22 & 2126 & 2.53 \\
\hline 22 & Stearic acid & 33.86 & 2360 & 2.78 \\
\hline
\end{tabular}


هستند. از اين ماده 9٪/\%٪ در محلـول ايـن نمونسه يافـت

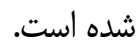

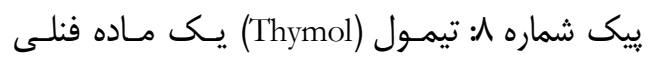

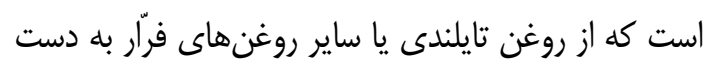

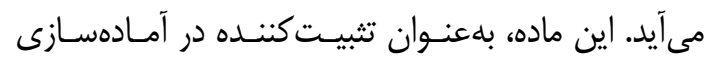

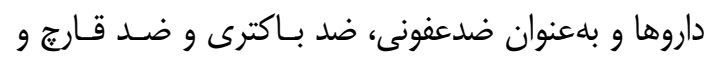

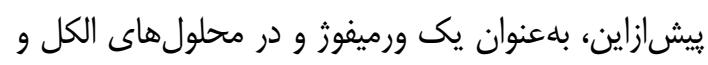

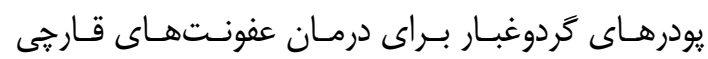

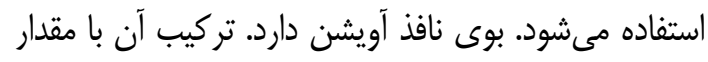

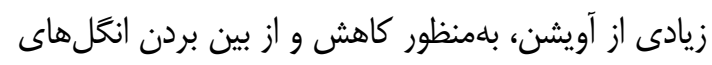

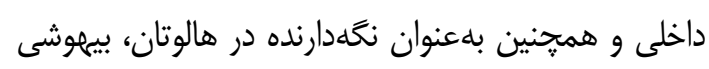

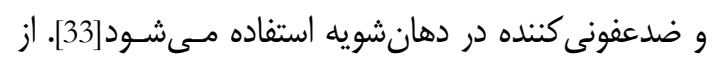
اين ماده هه/ \$٪ در محلول اين نمونه يافت شده است.

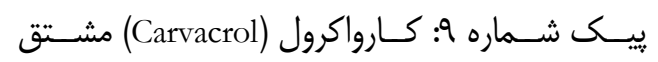

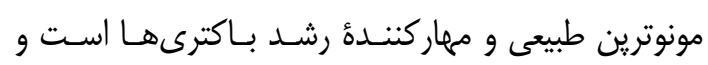

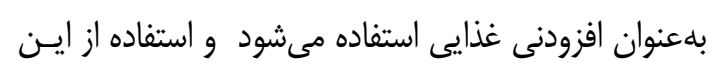

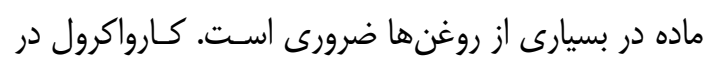

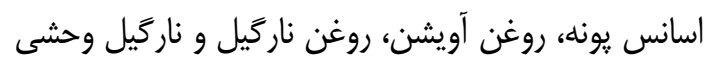

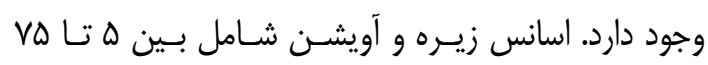

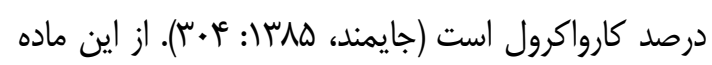

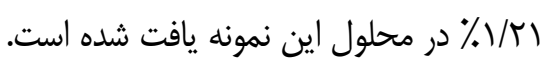

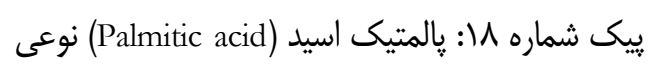

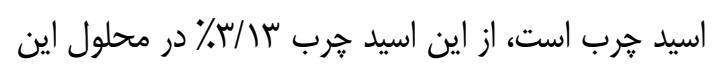
نمونه يافت شده است. ييك شماره זr: اسيد استئاريك (Stearic acid) يك اسيد هرب طبيعى است و در گياهان مختلف ازجمله كَّل

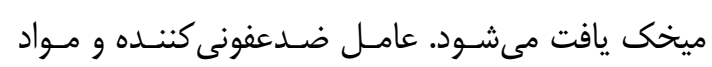

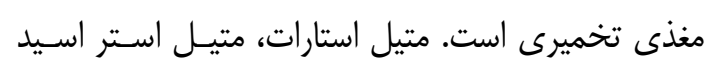

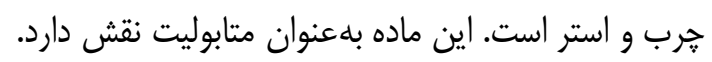

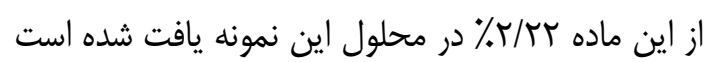

\section{1. نتيجه كيرى}

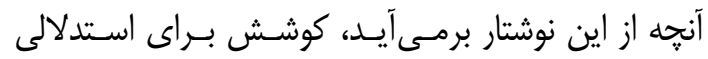

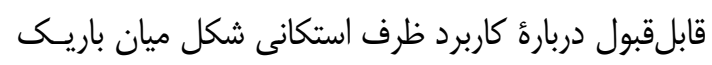

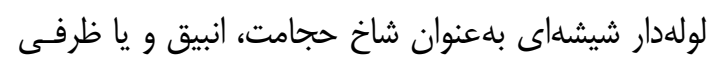

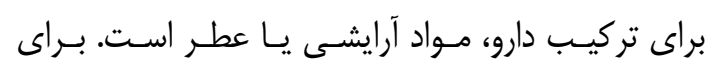
$|\mu|$
سايمن و كاما تريينن با مـواد روغنسى (يالميتيـك اسـيد و

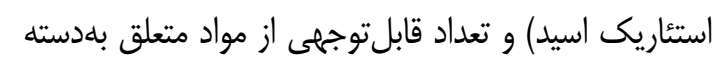

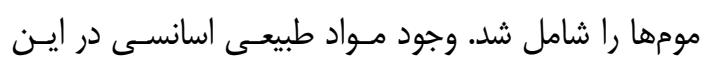

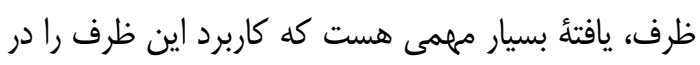

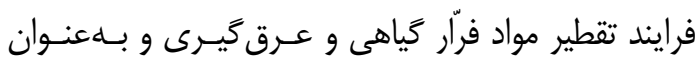

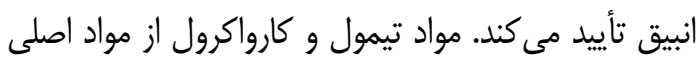
تشكيل دهنده اسانس هاى طبيعى هســتند كـه در كياهـان

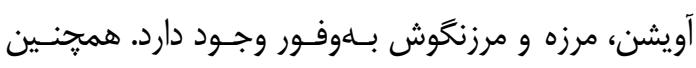

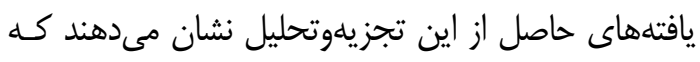

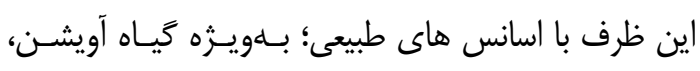

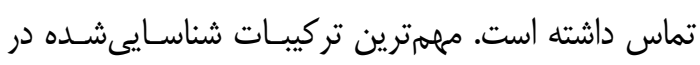

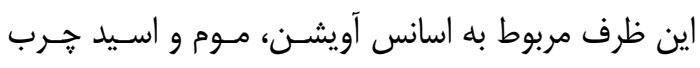

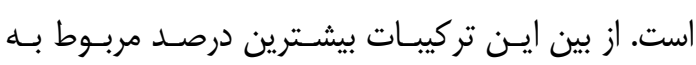
ساختارهاى شيميايى زير است: ييكى شماره ا: نونان (Nonane) يك آلكان مستتقيم

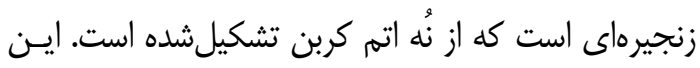

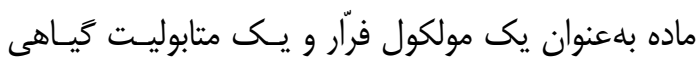

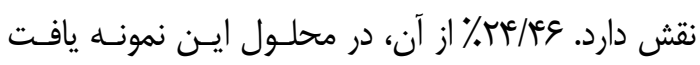
شده است.

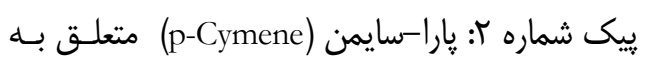
دسته مواد ترينوئيدى و اسانس هاى طبيعى است كه بيشتر

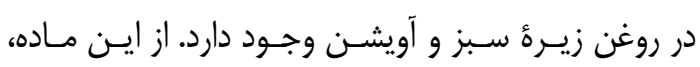

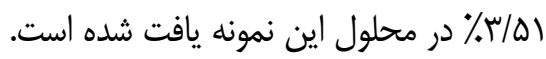

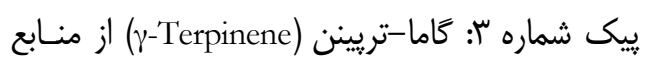

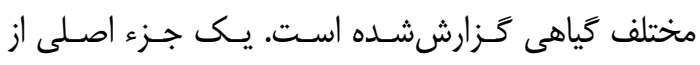

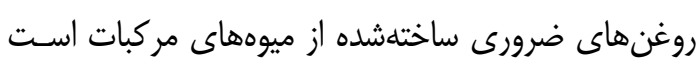

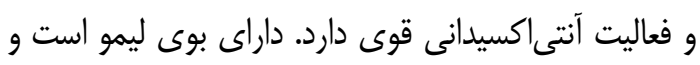

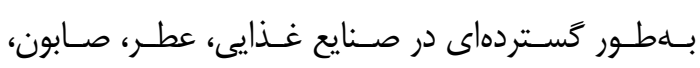

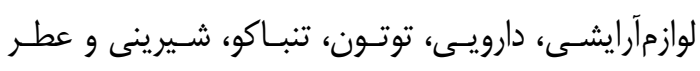

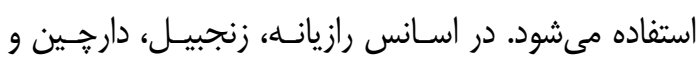

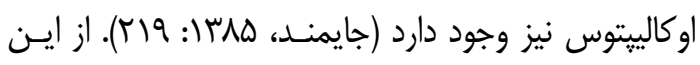
ماده ع /. ٪\% در محلول اين نمونه يافت شده است. ييك شـماره \&: ساليسـيل آلدهيـ (Salicylaldehyde)

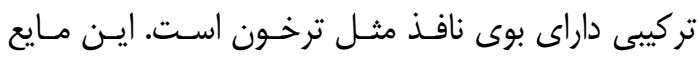

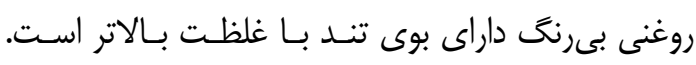

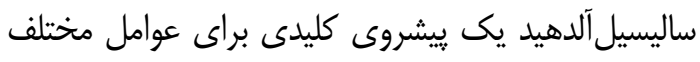

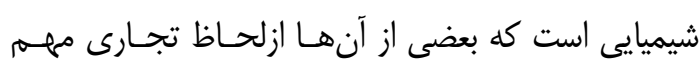


<smiles>CCc1ccc(C(C)C)c(O)c1</smiles>

thymol<smiles>Cc1ccc(C(C)C)cc1O</smiles>

carvacrol<smiles>CC(C)c1ccc(C(C)C)cc1</smiles>

p-cymene<smiles>CC1=CCC(C(C)C)=CC1</smiles>

gamma-terpinene salicylaldehyde

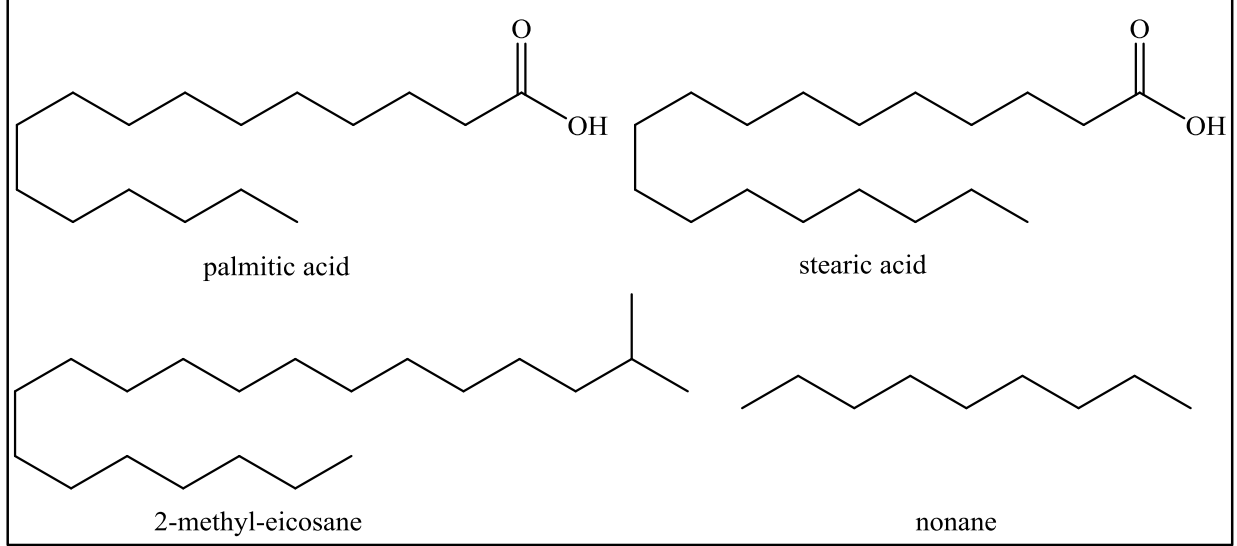

شكل م: ساختار شيميايى تركيبات اصلى شناسايى شده

Fig. 8: The chemical structure of main identified compounds

مطالعئ بنيادى دربارهُ كاربرد آنها و آزمايش نهشـتههـاى درون آنها، به كنار نهاده باشند.

\section{سياسگزارى}

اين مقاله بركرفته از تحقيقات صورت كرفته در باياننامـهـ دكتراى باستانشناسى نفيسه حسـينيان يكانـه بـا عنــان

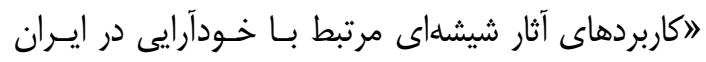

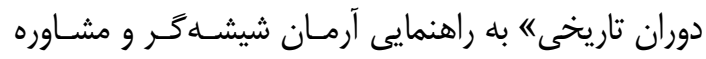

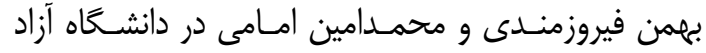

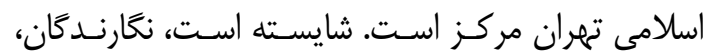

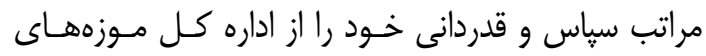

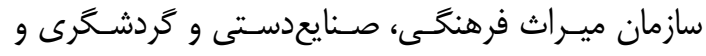

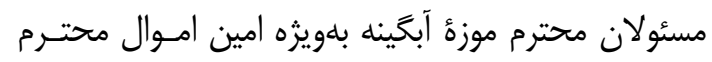
سركار خانم زهره محمديان مغاير براى همكارى صميمان مانه

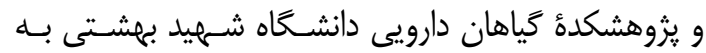

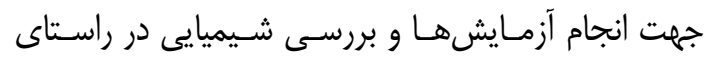

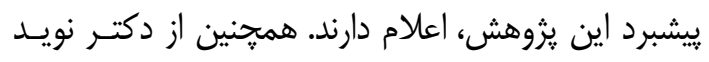

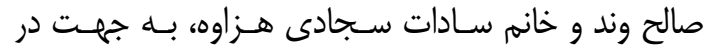
اختيار قرار نهادن عكس سه ظرف، سباسخزارى مى شئود.
دستيابى به اين مهم، نهشتههاى درون يكسى ازايـن گونـهـ

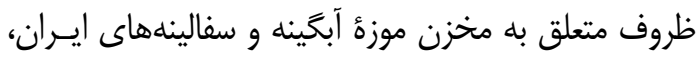

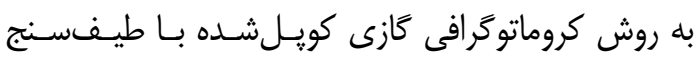

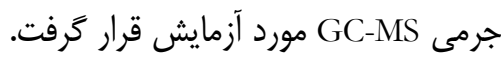

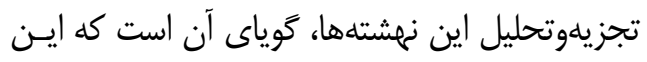

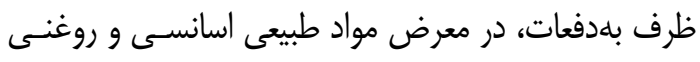

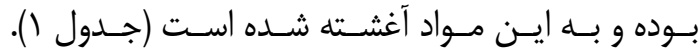

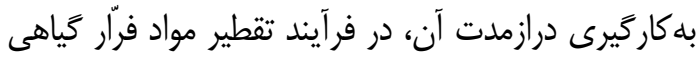

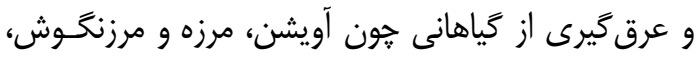

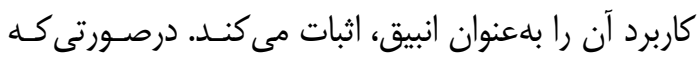

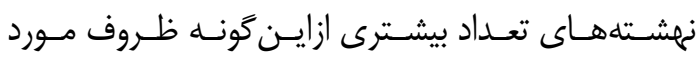

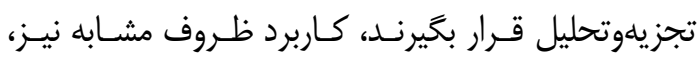

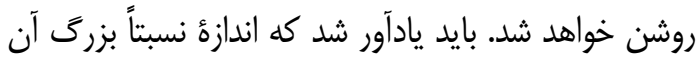

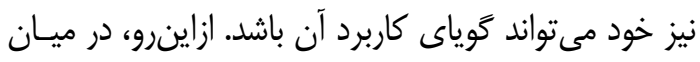

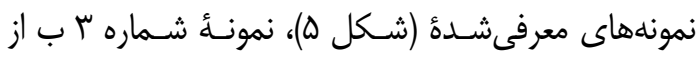
شوش نيز، ممكن است انبيق باشد و اين آزمايش مىتواند

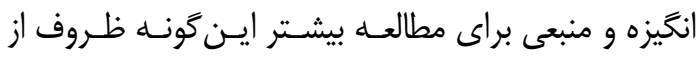

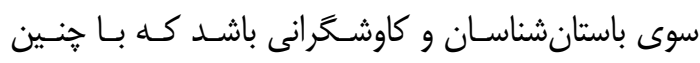
ظروفى برخورد مى كنند و ممكن است اين ظروف را بدان الدون

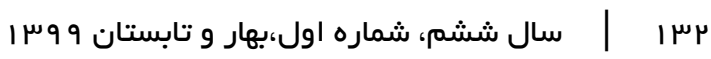


نسخة كتابخانهاى سـنيترزبـورى و تويكايى نيـز باآنكـهـ مشخص نيست كه بادكش در دست حجـامتخر، داراى لولهـ

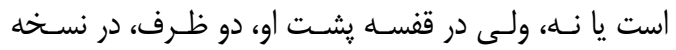
نخست با لوله كشيده و در نسخه دوم خميده، ترسيمشاهدانسـ

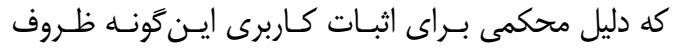

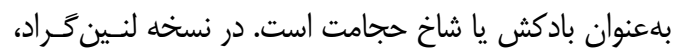
بادكشها بسيار شبيه استكانهاى كمر باريك سنتى هستند

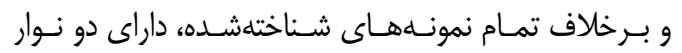

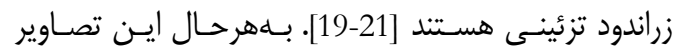

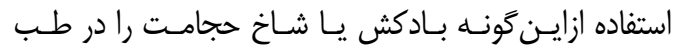

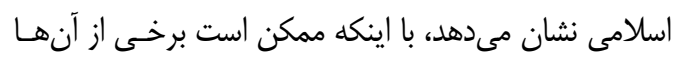

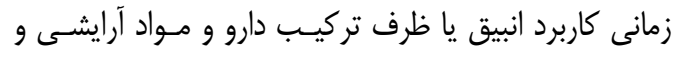

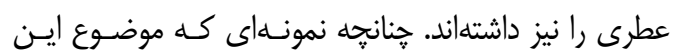
نوشتاراست، اين مطلب را نشان مى دهد (شكل هان مان.

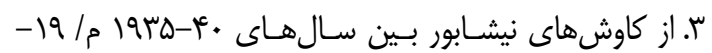

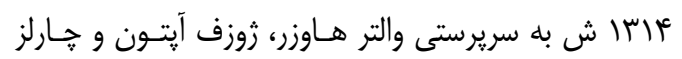

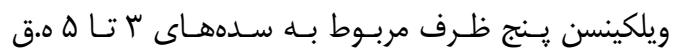
بلددستآمدهاند كه كروكر آنها را را بهعنوان انبيق منتشر كرده

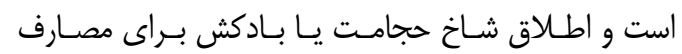

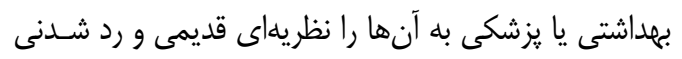

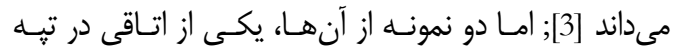

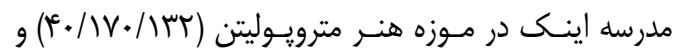

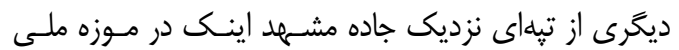

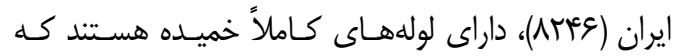

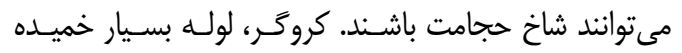

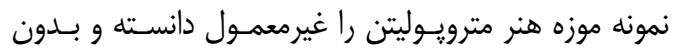

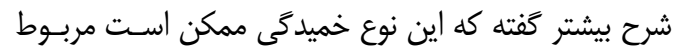
به كاربرد آن باشد [3,28].

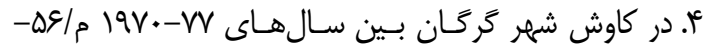
qجآ ش به سريرستى محمديوسف كيانى انجامشده است. در ميان يافتههاى شيشهاى كه در موزه ملى ايران نكمهدارى

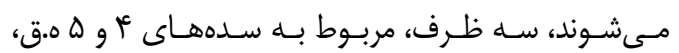

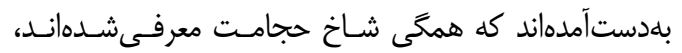

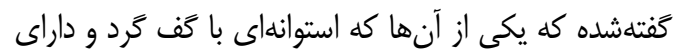

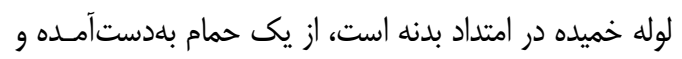

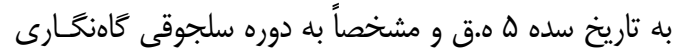

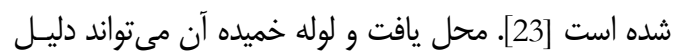

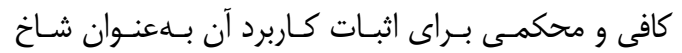

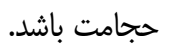

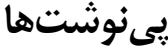

1. دوين يكى از بزركترين شهرهاى ســدهـاى ميـانى دوران

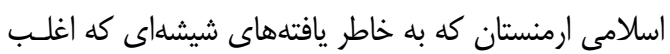

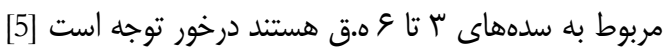

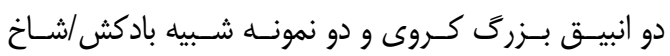

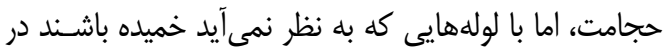

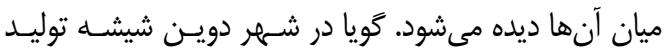

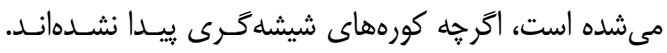

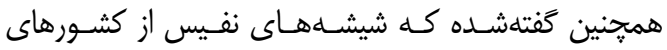

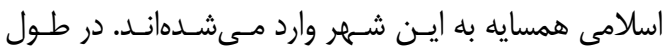

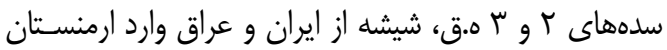

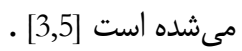

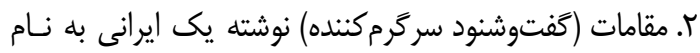

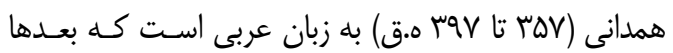

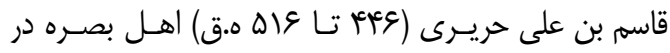

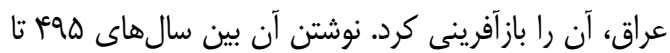

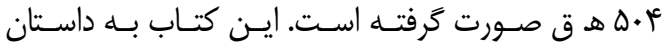

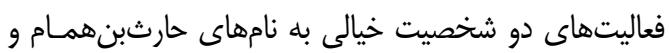

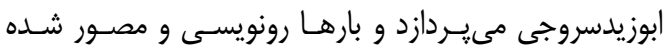

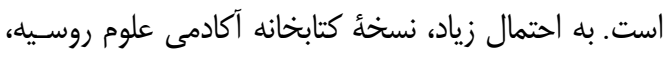

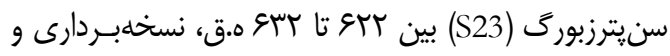
نقاشى شده و نسخه موردنظر كروكر است. نسخخه ديخـر در

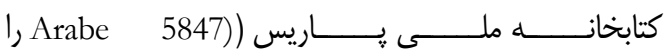

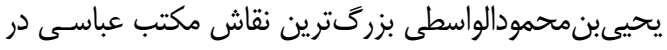

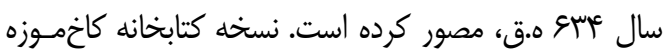

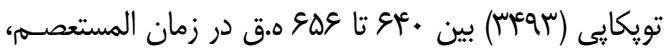

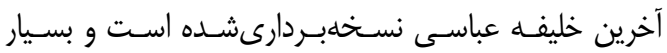

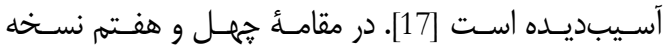
كتابخانه ملى ياريس كه در شهرى به نام حجم الى مامه در

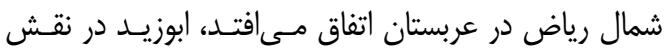

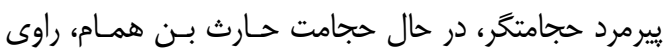

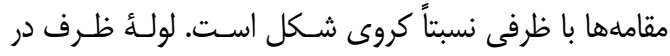
دست راست او قراركرفته و با آن كه بيشتر آن ازنظـر ينهـان

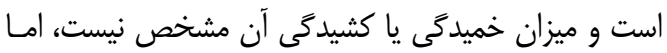

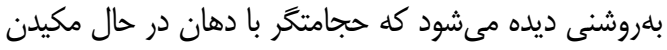

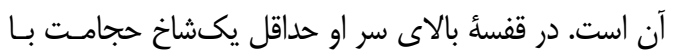

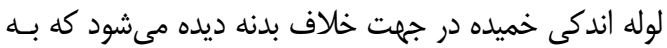

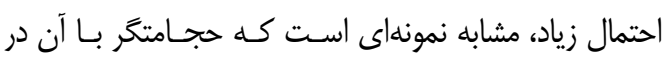
حال حجامت اسـت [18]. در مقامـــ جهــل و هفـتمه هـر دو 


\section{References}

[1] Al_hassan A.Y, Hill D.R. Islamic Technology, An Illustrated History. Paris: Unesco; 1992.

[2] Ar-Razis M.Z. Kitab al-asrar or Secret of alchemy. Translated by Hassan Ali Sheybany. Tehran: Tehran University; 1970. [in Persian]

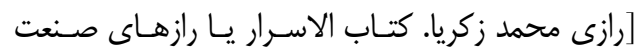

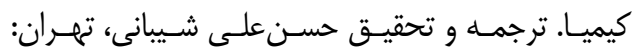

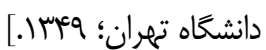

[3] Kroger J, Kröger J. Nishapur: glass of the early Islamic period. Metropolitan Museum of Art; 1995.

[4] https://www.ssplprint.com/image/83020 /islamic-sublimation-and-alembicapparatus-10th-12th-century

[5] Science and society Museum of london / Science \& Society Picture Library Image in the Internet].Nodate [Update Nodate, cited 2020 May 25] Available from: https://www.scienceandsociety.co.uk/res ults.asp?image $=10221242$

[6] Janpoladian HM. The Medieval Glassware of Dvin. The Archaeological Monuments and Specimens of Armenia. 1974; 7:80-2.

[7] Bass GF, Lledo B, Matthews S, Brill RH. Serçe Limani, Vol 2: The Glass of an Eleventh-Century Shipwreck. Texas A\&M University Press; 2009 Jul 20: 377-384.

[8] Carboni S, Brill RH, Whitehouse D, Gudenrath W. Glass of the Sultans. Metropolitan Museum of Art; 2001.

[9] Sajjadi Hazaveh L.S. Ahamadi, N. Alembics from Tower No.1 of Bam Citadel. 4th Iranian National Archaeological Conference, Birjand University; 2019, Sponsored by Civilica. [in Persian]

سجادى هزاوه ليلا سادات، احمدى نر گس. انبيق هـا در

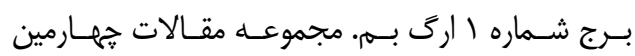

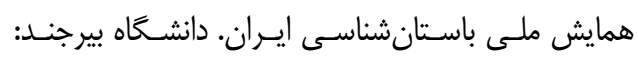

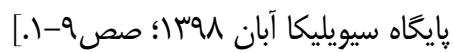

[10] Ghaini F. Glassware \& Ceramic Museum of Iran. Tehran: General Directorate of Education; 2004. [in Persian]

[قائينى فرزانه. موزه آبخينه و سفالينه هاى ايران. تهران: اداره

$$
\text { كل آموزش؛ سمسبا.] }
$$

[11] Nasr SH. Islamic science: an illustrated study.

[12] Al-Hassani ST. 1001 inventions: The enduring legacy of Muslim civilization. National Geographic Books; 2012.

[13] Thevet A. La Cosmographie Vniverselle D'André Thevet Cosmographe Dv Roy, Paris: Pierre l'Huilier, Binding II; 1575. [in French]

[14] Wulff HE. The traditional crafts of Persia: Their development, technology and influence on Eastern and Western civilizations.

[15] Nasr SH. Science and civilization in Islam. Cambridge, MA: Harvard University Press; 1968 Jan 1.

[16] Kheirandish,H, Shojaeeefar E \& Alipasha Meysamie A. Role of Cupping in the treatment of different diseases. systematic review article. Tehran: Univ Med J (TUMJ) 2017 March;74(12):829-42. [in Persian]

]خيرانديش حسين، شجاعىفر احسان، رياشا ميثمى على.

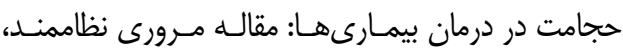

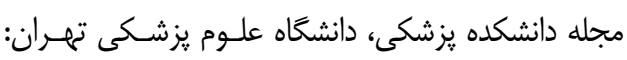

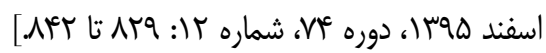

[17] Maddison F, Savage-Smith E. Science, Tools \& Magic: Body and Spirit, Mapping the Universe. Nour Foundation; 1997.

[18] Ettinghausen R. Grabar O. The Art and Architecture of Islam. 650-1250 United States: Yale University Press New Haven, CT; 1994.

[19] NATIONAL LIBRARY OF FRANCE[Image in the Internet].Nodate [Update Nodate, cited 2020 May 25] Available from: https://gallica.bnf.fr/ark:/12148/btv1b84 22965p/f318.item.rtl.zoom

[20] Kurzmann P. Einige Glasgeräte der arabischen Alchemie. Sudhoffs Archiv. 2009 Jan 1:184-200.

[21] Grabar O. A Newly Discovered Illustrated Manuscript of the" Maqāmāt" of Harīri. Ars Orientalis. 1963 Jan 1:97-109.

[22] Bolshakov OG. The St. Petersburg Manuscript of the Maqamat by al-Hariri and its Place in the History of Arab Painting. Manuscripta Orientalia. 1997 Dec;3(4):1997.

[23] NATIONAL LIBRARY OF FRANCE [Image in the Internet].Nodate [Update Nodate, cited 2020 May 25] Available

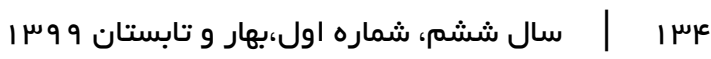


from:

https://gallica.bnf.fr/ark:/12148/btv1b84 22965p/f318.item.rtl.zoom

[24] Kordmahini, H. A. The Glass, in Kiani, M. Y. The Islamic City of Gurgan. AMI, suppl. vol. II. Berlin: 1984

[25] Dieulafoy M. L'acropole de Suse: d'après les fouilles exécutées en 1884, 1885, 1886, sous les auspices du Musée du Louvre. Hachette; 1893. [in French]

[26] Lamm CJ. Les verres trouvés à Suse. Syria: Volume 12, Issue 41931 Jan 1; p.358-367. [in French]

[27] The Metropolitan Museum of Art [Image in the Internet].2009[Update nodate. cited 2020 May 25] Available from: https://www.metmuseum.org/art/collecti on/search/449825

[28] Musee du Louvre Editions Cataloge/ Louvere editions. [Image in the Internet].2012[Update 2019 sep 22 cited 2020 May 25] Available from:

http:/ / cartelen.louvre.fr/cartelen/visite? $\mathrm{srv}_{\mathrm{O}}=$ bj_view_obj\&objet=cartel_17415_22805_ MAOS528.002.jpg_obj.html\&flag=true

[29] Hatami F. Susa Alembic Glass. Proceeding of National Museum of Iran(1), Tehran: National Museum of Iran \& Tanian; 2005, pp.71-83 [in Persian]

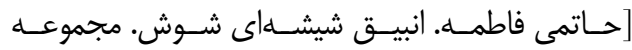

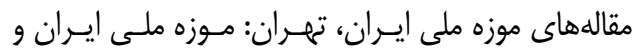

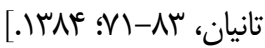

[30] Whitcomb DS. Before the roses and nightingales: excavations at Qasr-i Abu Nasr, Old Shiraz. Metropolitan Museum of Art; 1985.

[31] Faryadian, B. The first new season of excavation of the historical city of Saymareh. Ilam province, Cultural
Heritage, Handicrafts and Tourism Organization, Dare Shahr Historical Site Research Database, Iranian Center for Archaeological Reserch; 2009. [in Persian]

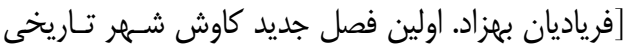

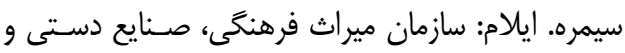

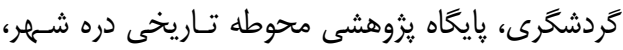

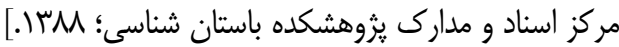

[32] Bozin B, Mimica-Dukic N, Samojlik I, Jovin E. Antimicrobial and antioxidant properties of rosemary and sage (Rosmarinus officinalis L. and Salvia officinalis L., Lamiaceae) essential oils. Journal of agricultural and food chemistry. 2007 Sep 19;55(19):7879-85.

[33] Colombini, M.P. and Modugno, F. eds. 2009. Organic mass spectrometry in art and archaeology. John Wiley \& Sons.

[34] Jaymand K, Rezaee M.B, Essentional oils, Distillations apparatuses, test methods of essential oils and retention indices in essentinal oil analysis. Iran; 2006 [in Persian]

$$
\begin{aligned}
& \text { ]جايمند كامكار، رضايى محمدباقر. اسانس، دستخاههـاى }
\end{aligned}
$$

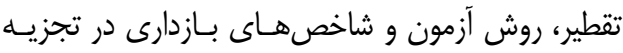

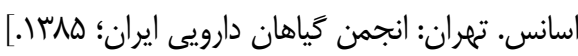

[35] Wikimedia Commons [Image in the Internet].2006[Update 12 November 2017, at 12:02. cited 2020 May 25] Available from:

https:/ / commons.wikimedia.org/wiki/Fil e:Cupping_glass_Louvre_MAOS705.jpg

[36] The Metropolitan Museum of Art [Image in the Internet].2009[Update nodate. cited 2020 May 25] Available from: https://www.metmuseum.org/art/collecti on/search/449405 